\title{
Endogenous Opioid-Induced Neuroplasticity of Dopaminergic Neurons in the Ventral Tegmental Area Influences Natural and Opiate Reward
}

\author{
Kyle K. Pitchers, ${ }^{1,2}$ Caroline M. Coppens, ${ }^{1}$ Lauren N. Beloate, ${ }^{3}$ Jonathan Fuller, ${ }^{1}$ Sandy Van, ${ }^{1}$ Karla S. Frohmader, ${ }^{1}$ \\ Steven R. Laviolette, ${ }^{1}$ Michael N. Lehman, ${ }^{1,3}$ and Lique M. Coolen ${ }^{1,2,3,4}$ \\ ${ }^{1}$ Department of Anatomy and Cell Biology, University of Western Ontario, London, Ontario, Canada N6A 3K7, ${ }^{2}$ Department of Psychology, University of \\ Michigan, Ann Arbor, Michigan 48109, ${ }^{3}$ Departments of Neurobiology and Anatomical Sciences, and ${ }^{4}$ Physiology and Biophysics, University of Mississippi \\ Medical Center, Jackson, Mississippi 39216
}

\begin{abstract}
Natural reward and drugs of abuse converge on the mesolimbic pathway and activate common mechanism of neural plasticity in the nucleus accumbens. Chronic exposure to opiates induces plasticity in dopaminergic neurons of the ventral tegmental area (VTA), which regulates morphine reward tolerance. Here, we test the hypotheses that mating-induced release of endogenous opioids in the VTA causes morphological changes of VTA dopamine cells in male rats, which in-turn regulate the long-term expression of experience-induced reinforcement of sexual behavior. First, sexual experience decreased VTA dopamine soma size 1 and 7 days, but not 30 days after the last mating session. This effect was blocked with naloxone before each mating session; thus, VTA dopamine cell plasticity was dependent on action of endogenous opioids. In turn, VTA plasticity was associated with altered opiate reward, as sexually experienced males did not form conditioned place preference for $0.5 \mathrm{mg} / \mathrm{kg}$ morphine. Next, it was determined whether endogenous opioid action mediates sexual reward and memory in male rats treated with naloxone during mating experience, either systemically or intra-VTA. Naloxone did not prevent the initial experience-induced facilitation of sexual behavior over repeated mating sessions, or conditioned place preference for mating. However, naloxone treatment attenuated the longer-term expression of experience-induced facilitation of sexual behavior and neural activation in mesolimbic areas induced by mating-associated conditioned cues. Together, these data demonstrate that endogenous opioids during mating induce neural plasticity in VTA dopamine neurons that appear critical for morphine reward and long-term memory for natural reward behavior.
\end{abstract}

Key words: dopamine; memory; mesolimbic; morphine; reward; ventral tegmental area

\section{Introduction}

Natural reward behaviors are mediated by the mesocorticolimbic system (Meisel and Mullins, 2006; Hoebel et al., 2009; Frohmader et al., 2010a; Pitchers et al., 2010a; Young et al., 2011; Blum et al., 2012). Drugs of abuse cause neural alterations in this system, which in-turn contribute to development and expression of substance abuse (Hyman et al., 2006; Nestler, 2012). We previously determined that experience with natural reward behavior, i.e., sexual experience in male rats, also causes neural plasticity in the nucleus accumbens (NAc), including increased dendritic spines (Pitchers et al., 2010a) and deltaFosB (Pitchers et al., 2013). Inturn, this sex-induced plasticity is critical for the effects of sex

Received Jan. 12, 2014; revised May 17, 2014; accepted May 20, 2014.

Author contributions: K.K.P., C.M.C., J.F., K.S.F., S.R.L., M.N.L., and L.M.C. designed research; K.K.P., C.M.C., L.N.B., J.F., S.V., K.S.F., and L.M.C. performed research; K.K.P., C.M.C., L.N.B., J.F., S.V., K.S.F., and L.M.C. analyzed data; K.K.P., C.M.C., L.N.B., S.R.L., M.N.L., and L.M.C. wrote the paper.

This research was supported by grants from the Canadian Institute of Health Research to L.M.C. and Natural Sciences and Engineering Research Council to K.K.P.

The authors declare no competing financial interests.

Correspondence should be addressed to Dr Lique M. Coolen, University of Mississippi Medical Center, Department of Physiology and Biophysics, 2500 North State Street, Jackson, MS 39216-4505. E-mail: Icoolen@umc.edu.

DOI:10.1523/JNEUROSCI.0133-14.2014

Copyright $\odot 2014$ the authors $\quad 0270-6474 / 14 / 348825-12 \$ 15.00 / 0$ experience on subsequent mating, manifested as the facilitation of initiation and performance of sexual behavior (Pitchers et al., 2010b, 2012, 2013). Moreover, sex experience alters responsiveness to psychostimulants, including sensitization of locomotor activity and enhanced reward (Frohmader et al., 2010a; Pitchers et al., 2010a, 2013).

The NAc is one downstream target of the dopaminergic neurons in the ventral tegmental area (VTA). VTA dopamine neurons are activated during mating and following exposure to conditioned cues predictive of sexual reward (Balfour et al., 2004; Frohmader et al., 2010a), through endogenous opioid peptide (EOP)-binding at $\mu$-opioid receptors (MORs; Matthews and German, 1984; Johnson and North, 1992; Klitenick et al., 1992; Ikemoto et al., 1997; Balfour et al., 2004). Hence, exposure to conditioned cues predictive of sexual behavior causes release of EOP and VTA dopamine-cell activation, which facilitates sexual motivation (Mitchell and Stewart, 1990; van Furth et al., 1995; van Furth and van Ree, 1996) and dopamine release in the NAc (Fiorino et al., 1997).

Repeated exposure to exogenous opiates causes morphological changes in the VTA (Mazei-Robison et al., 2011; MazeiRobison and Nestler, 2012), reduced soma size of VTA dopamine neurons (Sklair-Tavron et al., 1996; Spiga et al., 2003; Chu et al., 
2007; Russo et al., 2007; Mazei-Robison et al., 2011), decreased levels of neurofilament proteins (Beitner-Johnson et al., 1992), increased excitability of dopamine cells, and reduced axoplasmic transport and dopamine output to the NAc (Beitner-Johnson et al., 1992; Mazei-Robison et al., 2011). These VTA dopamine neuron changes cause morphine reward tolerance and are transient as they dissipate within a month of drug abstinence (Russo et al., 2007). It is currently unclear whether plasticity in the VTA dopamine neurons is unique to the actions of opiates or if they are also produced by the release of EOP during natural rewarding behaviors.

Here, we test the hypothesis that natural reward experience causes neuroplasticity similar to that caused by opiates, and thus, that opiates converge on a plasticity mechanism that is critical for natural reward behavior and reward memory. We test whether sexual experience in male rats reduces the soma size of VTA dopamine neurons via a process dependent on EOP action in the VTA. Furthermore, we investigate whether EOP-induced alterations in VTA dopamine neurons are associated with the reinforcement of natural rewarding behavior and the attribution of incentive salience to cues associated with natural reward, while causing cross-tolerance to morphine reward.

\section{Materials and Methods}

Animals

Adult male Sprague-Dawley rats (200-225 g) were obtained from Charles River and housed in pairs in artificially lighted rooms on a $12 \mathrm{~h}$ light/dark cycle in all experiments (lights off at 10:00 A.M. except for the morphine tolerance experiment, lights off at 5:00 P.M.). Food and water were available ad libitum except during behavioral testing. Stimulus females were ovariectomized and implanted subcutaneously with $5 \% 17$ $\beta$-estradiol benzoate SILASTIC capsules ( $1.98 \mathrm{~mm}$ inner diameter, $0.5 \mathrm{~cm}$ length, Dow-Corning). Injections of progesterone (subcutaneous, $500 \mu \mathrm{g}$ in $0.1 \mathrm{ml}$ of sesame oil) were administered 3-6h before testing to induce sexual receptivity. All procedures were approved by the University of Western Ontario and University of Michigan Animal Care Committees, and conformed to Canadian Council on Animal Care and National Institutes of Health guidelines involving vertebrate animals in research.

\section{Time course of VTA dopamine soma size changes}

Daily mating sessions. To study the time course of changes in dopamine neuron soma size in the VTA, sexually experienced and naive animals were killed at 1,7 , or $31 \mathrm{~d}$ ( $n=5-8$ per group) after the last day of mating (experienced) or handling (naive). Sexually experienced groups were matched for sexual behavior during the final mating session, as well as total numbers of ejaculations over the five sessions (average of 5 for each group), and did not differ in any parameter of sexual behavior.

Mating sessions. Sexually naive males were assigned to either of two experimental conditions: sexually naive or sexually experienced. Sexually experienced animals were allowed to mate five times on consecutive days with receptive females in rectangular test cages $(60 \times 45 \times 50 \mathrm{~cm})$ until display of ejaculation or up to $1 \mathrm{~h}$ (whichever came first). Cages were thoroughly cleaned with $70 \%$ ethanol solution and fresh bedding was added between mating sessions. Sexual behavior was performed during the dark phase (2-6 h after onset of dark). Only animals that ejaculated during at least four of the five mating sessions were considered sexually experienced and included in experiments. All mating sessions were observed and sexual behavior was recorded. The number of mounts (M) intromissions (IMs), mount latency (ML; time from introduction of the female to first mount), intromission latency (IL; time from introduction of the female to first intromission), and ejaculation latency (EL; time from first intromission to ejaculation) were recorded (Agmo, 1997). Naive animals were placed in a clean test cage for $1 \mathrm{~h}$ concurrently with sexually experienced males mating in the same room, such that they were exposed to distant female odors, and similar levels of disturbance and environmental novelty as experienced males.

Immunofluorescence labeling. Animals were deeply anesthetized using sodium pentobarbital ( $270 \mathrm{mg} / \mathrm{kg}$, i.p.) and perfused intracardially with
$50 \mathrm{ml}$ of $0.9 \%$ saline, followed by $500 \mathrm{ml}$ of $4 \%$ paraformaldehyde in 0.1 M sodium phosphate buffer (PB). Brains were removed and postfixed for $1 \mathrm{~h}$ at room temperature (RT) in the same fixative, and then immersed in $20 \%$ sucrose and $0.01 \%$ sodium azide in $0.1 \mathrm{M} \mathrm{PB}$ for storage at $4^{\circ} \mathrm{C}$. Coronal sections were cut at $35 \mu \mathrm{m}$ on a freezing microtome (H400R, Microm) and were collected in four parallel series in cryoprotectant solution (30\% sucrose, $30 \%$ ethylene glycol in $0.1 \mathrm{M} \mathrm{PB})$ then stored at $20^{\circ} \mathrm{C}$. All incubations were performed at RT with gentle agitation and copious rinses with $0.1 \mathrm{M}$ PBS, pH 7.35, between incubations. Sections were exposed to $1 \% \mathrm{H}_{2} \mathrm{O}_{2}$ for $10 \mathrm{~min}$ to destroy endogenous peroxidases, then blocked for $1 \mathrm{~h}$ in incubation solution (PBS+: PBS containing $0.4 \%$ Triton X-100; Sigma-Aldrich) and 0.1\% bovine serum albumin (Jackson Immuno Research Laboratories). Next, sections were incubated overnight at RT in a mouse tyrosine hydroxylase (TH)-antibody (1:20 000; Millipore). After primary antibody incubation, sections were incubated in AlexaFluor 555-conjugated goat anti-mouse antibody (1:100; Invitrogen, Eugene, OR) for $30 \mathrm{~min}$. Finally, sections were washed with $0.1 \mathrm{M} \mathrm{PB}$, mounted on Superfrost Plus glass slides, dried, and coverslipped with gelvatol containing the anti-fading agent 1,4-diazabicyclo(2,2)octane (DABCO; 50 mg/ml, Sigma-Aldrich; Lennette, 1978).

Data analysis: neuron soma size. Images of TH-immunoreactive (IR) neurons in the VTA were taken at $40 \times$ magnification at three rostral to caudal levels (Balfour et al., 2004). There were no differences detected between cells at the different levels. The soma size of TH-IR neurons was analyzed using ImageJ (National Institutes of Health). Mean area, perimeter, and circularity were measured as described by Sklair-Tavron et al. (1996). An average of 25 cells per animal (combined all 3 VTA levels) was analyzed and only cells with a clearly visible nucleus were included. For each animal, the mean area, perimeter, and circularity were calculated. For statistical analysis a two-way ANOVA was used [factors: sexual experience (sex experienced or sex naive) and time $(1,7$, or $31 \mathrm{~d})]$ followed by post hoc comparisons using the Holm-Sidak method with a significance level of 0.05 .

\section{VTA non-dopamine changes}

Biweekly mating sessions. To test whether sexual experience during daily mating sessions is required for decreases in TH-IR neuron soma size, VTA dopamine neurons of animals that had mated during five biweekly mating sessions were analyzed. Mating sessions were as described above, but over a period of 2.5 weeks. Brains were collected $7 \mathrm{~d}$ after last mating or handling.

Immunoperoxidase labeling. In addition, it was tested whether using sensitive staining techniques with immunoperoxidase and chromogen detection, would also allow for the visualization of TH-IR soma size changes. Perfusion and tissue processing was conduct as described above. Following treatment with $1 \% \mathrm{H}_{2} \mathrm{O}_{2}$ and $\mathrm{PBS}+$, sections were incubated overnight at RT in a mouse polyclonal tyrosine hydroxylase (TH)antibody (1:20 000; Millipore). After primary antibody incubation, sections were incubated with biotin-conjugated goat anti-rabbit IgG $(1 \mathrm{~h}$, 1:500 in PBS+; Vector Laboratories), avidin-biotin-horseradish peroxidase (1 h, ABC elite; 1:1 000 in PBS; Vector Laboratories), and 3, 3 '-diaminobenzidine tetrahydrochloride (10 min, 0.02\%, DAB; SigmaAldrich) enhanced with nickel sulfate in $(0.02 \%$ in $0.1 \mathrm{M} \mathrm{PB})$ with hydrogen peroxide $(0.015 \%)$. Sections were washed thoroughly in $0.1 \mathrm{M}$ PB to terminate the reaction and mounted onto coded Superfrost plus glass slides (Fisher) with $0.3 \%$ gelatin in $\mathrm{dd}_{2} \mathrm{O}$. Following dehydration, all slides were coverslipped with DPX mountant (dibutyl phthalate xylene; Sigma-Aldrich).

Data analysis: neuron soma size. TH-IR cells were analyzed for area, perimeter, and circularity as described above. In addition, TH-IR cells in substantia nigra $(\mathrm{SN})$, in the same sections used for analysis of VTA TH-IR cells, were analyzed. Finally, following analysis of VTA and SN TH-IR cells, sections were counterstained using cresyl violet and non-TH-IR cells were analyzed using the same methods as described above. Differences between naive and experienced groups were compared using two-tailed Student's $t$ tests with a significance level of 0.05 . 


\section{Effects of naloxone on experience-induced dopamine soma size reduction}

To determine whether MORs played a role in sex experience-induced changes in dopamine neuron soma size, MOR were blocked during sexual behavior. Half of the animals gained sexual experience, whereas the other half were handled but remained sexually naive. Sexually experienced animals were allowed to mate on 5 consecutive days. Within the sexually experienced and naive groups, animals were treated with the nonselective MOR antagonist naloxone $(10 \mathrm{mg} / \mathrm{kg}$, s.c.; Sigma-Aldrich, dissolved in $0.9 \%$ saline) or saline 30 min before introduction of the female (experienced) or before handling (naive); thereby creating four experimental groups: sexually naive saline (Naive $\mathrm{Sal}$ ), sexually naive naloxone (Naive NLX), sexually experienced saline (Exp Sal), and sexually experienced naloxone (Exp NLX; $n=5-8$ per group). Naloxone treatment did not have statistically significant effects on any parameter of sexual behavior, on any of the $5 \mathrm{~d}$, and naloxone- and saline-treated groups were identical in sexual experience. All animals were killed via intracardial perfusion $7 \mathrm{~d}$ after last mating session. Sectioning, immunohistochemistry, and data analysis (twoway ANOVA; factors: sex experience and drug treatment) for dopamine soma size were conducted as described above.

\section{Morphine conditioned place preference}

Experimental design. Previously, Russo et al. (2007) showed chronic morphine induces tolerance to morphine reward. Since sexual experience and chronic morphine cause similar decreases in soma size of dopamine neurons in the VTA, the functional relevance of the sex-induced morphological changes were tested for morphine reward. Sexually experienced and naive animals were divided into six different experimental groups ( $n=9-13$ per group) based on sexual behavior (sexually naive or experienced) and morphine dose (0.5, 5.0, or $10.0 \mathrm{mg} / \mathrm{kg}$, i.p.) and were tested for morphine-induced conditioned place preference (CPP).

Morphine-CPP. Conditioning took place $1 \mathrm{~d}$ after the last mating session and groups were matched for sexual performance during the last mating session. The used CPP paradigm consisted of a pretest, conditioning days, and post-test, and apparatus was based on Tenk et al. (2009). Briefly, the CPP apparatus (MED Associates) consisted of three distinct chambers. Between each session, the apparatus was thoroughly cleaned with $70 \%$ ethanol solution to minimize lingering olfactory cues. To determine individual preferences, a pretest was conducted during which animals were given free access to the entire apparatus for 15 min. As a group, animals did not show significant preference for a specific chamber, but each individual animal had a slight initial preference. Rats that showed a substantial preference for one of the chambers $(>200 \mathrm{~s}$ difference between time spent in each of the chambers; $<5 \%$ of animals) during the pretest were excluded from the study. During conditioning, drug was paired to either initially preferred or nonpreferred chamber using an unbiased paradigm (Tzschentke, 2007) and animals were confined to the chambers for $30 \mathrm{~min}$. Animals were injected with saline (i.p.) in the morning (9:00 A.M. to 12:00 P.M.) and confined to the saline-paired chamber (control). In the afternoon (1:00-4:00 P.M.), animals were injected with morphine (i.p., $0.5 \mathrm{mg} / \mathrm{kg}, 5.0 \mathrm{mg} / \mathrm{kg}$ or $10.0 \mathrm{mg} / \mathrm{kg}$; morphine sulfate dissolved in $0.9 \%$ saline, Johnson Matthey) and confined to the morphine-paired chamber. Animals were subjected to two conditioning days. The next day ( $3 \mathrm{~d}$ after last day of mating) a post-test, procedurally identical to the pretest, was conducted. For statistical analysis, time spent in the morphine-paired chamber during the post-test was compared with the time spent in the saline-paired chamber during the post-test for sexually naive or experienced males within each dosage using a paired $t$ test. $p<0.05$ was considered statistically significant. Additional control groups of sexually naive and experienced animals received saline in both paired and unpaired chambers to serve as negative controls. No differences in time spent between chambers were detected for either group.

\section{Effects of systemic naloxone on experience-induced facilitation of sexual behavior}

Experimental design. Sexual experience results in the facilitation of sexual behavior that is maintained for at least 1 month (Pitchers et al., 2012). To analyze the effect of blocking MOR on experience-induced facilitation of sexual behavior, sexually experienced animals received either naloxone or saline before the five consecutive mating sessions ( $n=12$ each) as described above. One week after the last mating session, a final mating test was conducted during which all animals were allowed to mate until one ejaculation or up to $1 \mathrm{~h}$. No naloxone or saline treatment was administered before mating on the final test day. Parameters of mating were compared to determine whether naloxone affected either sex experienceinduced facilitation of mating (day 1 vs day 5) or maintenance of this facilitation (day 5 vs test) using a two-way ANOVA [factors: treatment (saline versus naloxone) and day (day 1, day 5, or test)] and Holm-Sidak method for post hoc comparisons. For all statistical tests, $p<0.05$ was considered to be statistically significant.

\section{Additional control experiments}

Systemic naloxone on test day. To show that altered sexual behavior on final mating test day was not due to the absence of naloxone, we administered either naloxone or saline on the final mating test day to animals that received mating paired with naloxone while they gained sexual experience. Specifically, all animals received naloxone injection $(10 \mathrm{mg} / \mathrm{kg}$, s.c.) 30 min prior mating to one ejaculation during 5 consecutive days. On test day $7 \mathrm{~d}$ later, approximately half the animals received an injection of naloxone $(10 \mathrm{mg} / \mathrm{kg}, n=7)$ or saline $(n=6) 30 \mathrm{~min}$ before introduction of a receptive female. Sexual behavior was observed and recorded. Parameters of mating were compared to determine whether naloxone affected either sex experience-induced facilitation of mating (day 1 vs day 5 ) or maintenance of this facilitation (day 5 vs test) using a two-way ANOVA [factors: treatment (saline versus naloxone) and day (day 1 , day 5, or test)] and Holm-Sidak method for post hoc comparisons. For all statistical tests, $p<5 \%$ was considered to be statistically significant.

Effects of naloxone on short-term expression of facilitated sexual behavior. The effects of naloxone $(10 \mathrm{mg} / \mathrm{kg}$, s.c.) treatment during mating was tested on subsequent sexual behavior during a final mating test day, which was conducted only $1 \mathrm{~d}$ after last mating (saline, $n=5$; naloxone, $n=4)$.

Systemic naloxone pretreatment. To determine whether it repeated treatment of naloxone alone causes impairment of sexual behavior $7 \mathrm{~d}$ after last treatment, sexually naive animals received five daily naloxone (10 mg/kg, s.c.) or saline injections on consecutive days before a mating test $7 \mathrm{~d}$ after final naloxone or saline injection. On this final test day, animals did not receive any injection. Sexual behavior was observed and recorded as described above. Parameters of mating were compared between groups using unpaired $t$ tests. For all statistical tests, $p<5 \%$ was considered to be statistically significant.

Systemic naloxone and sex reward. One possibility for naloxone's attenuating effects on the display of maintenance of facilitated sexual behavior is that naloxone blocks the rewarding effects of sexual behavior. To test this possibility, the CPP paradigm was conducted for sexual behavior immediately following naloxone or saline injection in males with no prior sexual experience. CPP procedure was similar to described above for morphine-CPP, including pretest, conditioning days, and post-test.

Sex behavior was paired with the initially nonpreferred chamber. In a counterbalanced manner, each animal received an injection of naloxone ( $n=12)$ or saline $(n=11) 30 \mathrm{~min}$ before receiving access to a receptive female. The average duration of mating session was $\sim 13 \mathrm{~min}$. One minute following ejaculation, the animal was placed in the paired chamber for $30 \mathrm{~min}$. On the other conditioning day, animals received an injection of either naloxone or saline (whichever they received before mating), and were placed into the unpaired chamber for $30 \mathrm{~min}$. Next, a post-test was conducted, identical to the pretest. To determine chamber preference, time spent in the paired chamber during the pretest and post-test was compared. For statistical analysis, paired $t$ tests were used to compare preference and difference scores, and time in paired chamber during the pretest and post-test to determine whether a significant CPP was formed for sexual behavior. $p<0.05$ was considered significant.

\section{Effects of intra-VTA naloxone on experience-induced facilitation of sexual behavior}

Experimental design. To determine whether EOP action specifically in the VTA, was responsible for the effects of sexual experience-induced 
changes on sexual behavior, animals underwent local infusion of naloxone or saline into the VTA before five daily mating sessions. Behavioral paradigm was similar to the systemic naloxone experiment. Sexually experienced animals were allowed to mate during 5 consecutive days until one ejaculation or up to $1 \mathrm{~h}$. Fifteen minutes before introducing the receptive female, the male rats received bilateral infusions of either naloxone $(10 \mu \mathrm{g} / \mu \mathrm{l}$ per hemisphere; $0.5 \mu \mathrm{l}$ volume; dissolved in $0.9 \%$ saline) or saline $(0.5 \mu \mathrm{l}$ per hemisphere). Bilateral microinjections were administered at a flow rate of $0.5 \mu \mathrm{l} / \mathrm{min}$ over a $1 \mathrm{~min}$ interval followed by an additional $1 \mathrm{~min}$ with the injection cannula left in place for diffusion. The injection cannula was then replaced with the dummy cannula and dust cap. One week after the final day of mating (test day), all animals mated once more to ejaculation without an infusion of naloxone or saline. Figure $3 A$ outlines the experimental design. Data analysis was conducted as described in systemic naloxone experiment.

Cannulation surgery. Male rats were anesthetized with an intraperitoneal injection $(0.1 \mathrm{ml} / \mathrm{kg})$ of ketamine $(0.87 \mathrm{mg} / \mathrm{ml})$ and xylazine $(0.13$ $\mathrm{mg} / \mathrm{ml}$ ), and placed into a stereotaxic apparatus (Kopf Instruments). Bilateral 21-gauge guide cannulas (Plastics One) were lowered through small drill holes in the skull into the brain toward the VTA at $-4.8 \mathrm{~mm}$ $\mathrm{AP}, \pm 0.75 \mathrm{~mm} \mathrm{ML}$ from bregma and $-7.8 \mathrm{~mm} \mathrm{DV}$ from the top of the skull according to Paxinos and Watson (2013). Cannulas were secured with dental acrylic that adhered to three screws set into the skull. Animals were given a 2 -week recovery period, and were handled daily for habituation to handling and injection procedures used during behavioral testing.

Cannula placement verification. The placement of the cannulas was examined using TH-immunostaining to confirm the VTA was accurately targeted. Only animals with proper placements were included in analyses (final group sizes: experienced saline $n=8$; experienced naloxone $n=6$ ). Three additional animals that received intra-VTA naloxone injections directed outside the VTA were grouped together in a "missed" injection group. The missed group was analyzed separately to serve as anatomical controls and Mann-Whitney $U$ test was used to compare behavior on final test day with naloxone and saline-treated experienced males.

\section{Mating-associated contextual cue-induced pERK expression}

Experimental design. Exposure to the cage in which males acquired mating experience has been shown to cause MOR activation in the VTA and neural activity in VTA and NAc (Balfour et al., 2004). Hence, the mating environment serves as a conditioned cue predictive of sexual reward. The current study tested whether MOR activation during sexual experience is required for subsequent conditioned cue-induced neural activation. Naloxone or saline was administered systemically (i.p.) 30 min before placement in the mating arena and the introduction of a receptive female for mating (experienced), or before the control manipulation which consisted of placement in the handling cage without presentation of the female (neutral environment; naive). Thus, four experimental groups were created: Naive Sal, Naive NLX, Exp Sal, and Exp NLX. One week after final mating session, half the animals in each group were exposed to the mating cage (Exp males: sex-associated conditioned cues) or handling cage (naive males: nonsalient/neutral cues), whereas the other half was not exposed to any cues and instead remained in the home cages (to determine baseline $\mathrm{pERK}$ expression). This experimental paradigm produced 8 groups: Naive Sal-No Cue, Naive Sal+Cue, Naive NLX-No Cue, Naive NLX+Cue, Exp Sal-No Cue, Exp Sal+Cue, Exp NLX-No Cue, Exp $\operatorname{NLX}+$ Cue ( $n=4$ each except Naive NLX-No Cue, $n=3)$. Animals were perfused 10-15 min after cue exposure. Control animals were removed from their home cages and perfused concurrently.

Immunohistochemistry. Sectioning and immunohistochemistry were conducted as described above. Here, we used a rabbit polyclonal antibody against p42 and p44 MAP Kinases ERK1 and ERK2 (pERK; 1:4 000; Cell Signaling Technology). The primary antibody has been extensively characterized in the literature (Roux and Blenis, 2004; Murphy and Blenis, 2006; Frohmader et al., 2010b). Moreover, omission of the primary antibody prevented all immunoreactivity and Western blot analysis of rat brain tissue revealed two bands at the appropriate molecular weights.

Data analysis. pERK-immunoreactive (-IR) cells were counted in a number of brain regions using a camera lucida drawing tube attached to
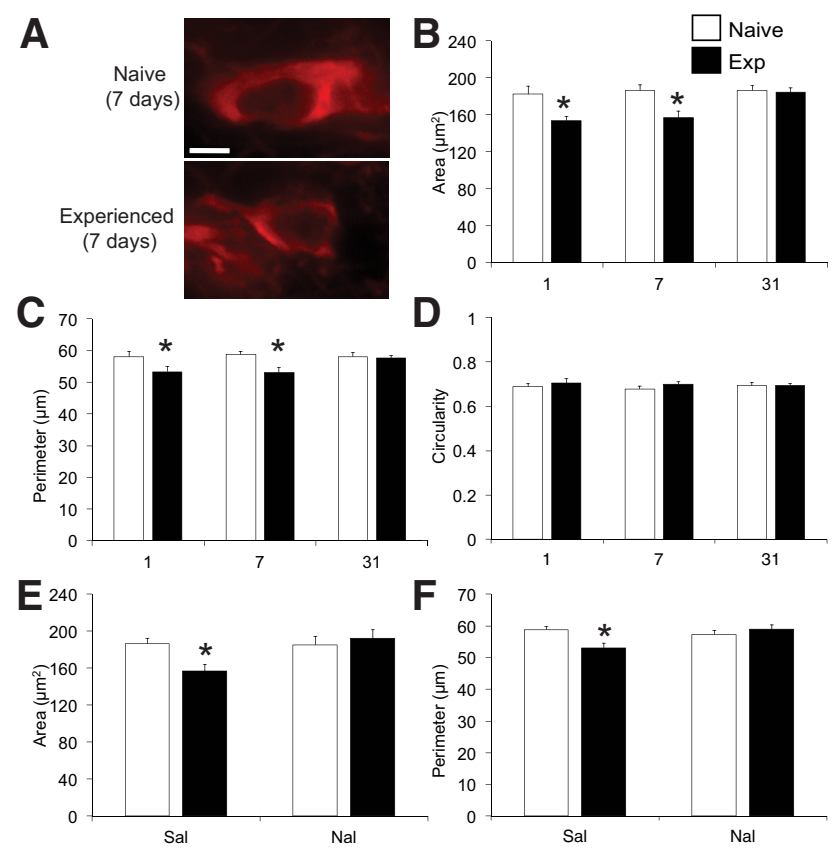

Figure 1. Endogenous opioid-induced soma size changes of VTA dopamine neurons. $\boldsymbol{A}$, Representative images of VTA dopamine neurons from sexually naive and experienced animals showing the reduction in soma size $7 \mathrm{~d}$ after final mating session. Scale bar, $5 \mu \mathrm{m}$. Quantitative data showing that sexual experience (Exp, black bars) caused significant reduction in area ( $\boldsymbol{B}$; in $\mu \mathrm{m}^{2}$ ) and perimeter ( $\boldsymbol{C}$; in $\mu \mathrm{m}$ ) of VTA dopamine cells, $1 \mathrm{~d}$ (Naive, Exp; $n=6$ ) and $7 \mathrm{~d}$ (Naive, $n=5$; $\operatorname{Exp}, n=6$ ), but not $31 \mathrm{~d}$ (Naive, $n=6$; Exp, $n=8$ ) after final mating, compared with sexually naive controls (Naive, white bars). Area was reduced to $84 \%$ in experienced males compared with naive controls at 1 or $7 \mathrm{~d}$. Perimeter was reduced to 91.6 and $90 \%$ in experienced groups compared with control at 1 and $7 \mathrm{~d}$ resp. There was no effect on circularity $(\boldsymbol{D})$. This dopamine cell plasticity in area $(\boldsymbol{E})$ and perimeter $(\boldsymbol{F})$ was prevented by naloxone (NLX, $n=8$ ), but not saline ( $S a l, n=7$ ) treatment during mating, $7 \mathrm{~d}$ after final mating session compared with sexually naive controls (Sal, $n=5 ; \mathrm{NLX}, n=6$ ). Data represent mean $\pm \mathrm{SEM}$; * indicates significant difference compared with sexually naive controls of the same day ( $\boldsymbol{B}$, $\boldsymbol{C})$ or compared with saline-treated sexually naive controls and naloxone-treated sexually experienced males $(\boldsymbol{E}, \boldsymbol{F})$.

a Leica DMRD microscope: NAc [core (C) and shell (S); $400 \times 600 \mu \mathrm{m}$; medial prefrontal cortex; $\mathrm{mPFC}$; anterior cingulate area (ACA); prelimbic cortex (PL); infralimbic cortex (IL); $600 \times 800 \mu \mathrm{m}$ each], caudateputamen $(\mathrm{CP} ; 800 \times 800 \mu \mathrm{m})$, and basolateral amygdala (BLA; $900 \times$ $1200 \mu \mathrm{m}$; Balfour et al., 2004; Frohmader et al., 2010b; Pitchers et al., 2010b). Two sections were counted per brain region and numbers of cells in the standard areas of analyses were then calculated as numbers of cells per $\mathrm{mm}^{2}$. The two counts were averaged per animal for calculation of group means. Group averages within sexually experienced or naive groups were compared using two-way ANOVA [factors: drug treatment (NLX or Sal) and cue (cue or no cue)] followed by post hoc comparisons using the Holm-Sidak or Mann-Whitney sum tests where appropriate with a significance level of $p<0.05$. In the NAc shell of sexually experienced animals, there was a strong trend toward significance of the factors and thus, pairwise comparisons were conducted to compare saline (Sal-No Cue) and saline cue (Sal+Cue) groups only.

Images. Digital images were captured using a CCD camera (Macrofire, Optronics) attached to a Leica microscope (DM5000B) with fixed camera settings. Images were imported into Adobe Photoshop 9.0 software. Images were not altered in any way except for adjustment of brightness and contrast.

\section{Results}

Sex experience-induced changes in VTA dopamine cells Sexual experience resulted in a decrease in VTA dopamine soma size (Fig. 1A-C). Sexual experience significantly reduced area and perimeter of the soma of VTA TH-IR cells (area: $F_{(1,31)}=23.068, p<$ 
A
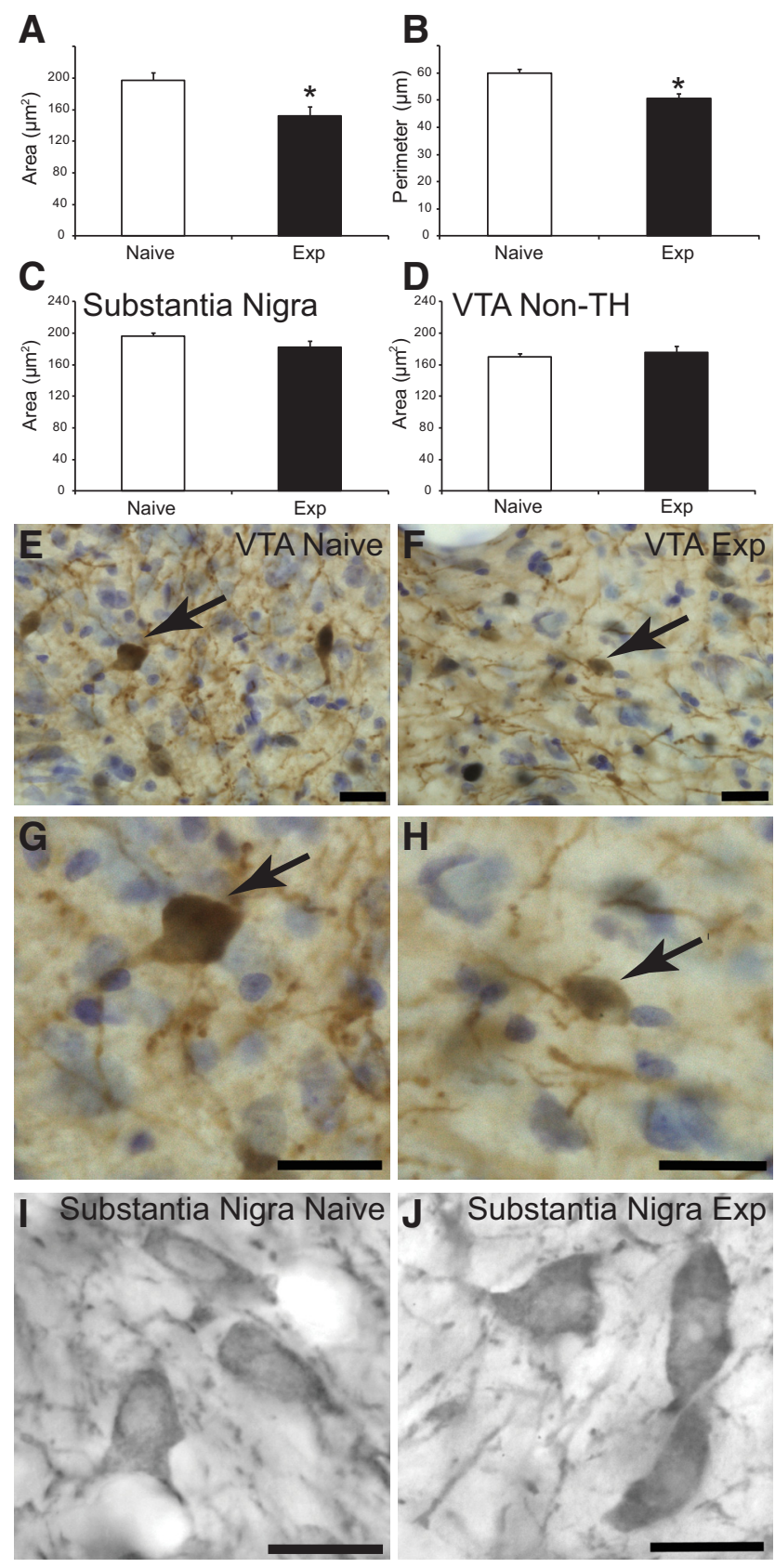

Figure 2. Sexual experience did not decrease soma size in substantia nigra dopamine neurons or VTA nondopamine neurons. VTA TH-IR neuron soma area $\left(\boldsymbol{A}\right.$; in $\left.\mu \mathrm{m}^{2}\right)$ and perimeter ( $\boldsymbol{B}$; in $\mu \mathrm{m}$ ) in sexually naive (white) and experienced (black) animals that gained experience by mating two times per week rather than during consecutive days. Substantia nigra TH-IR soma area ( $\boldsymbol{C}$ and VTA non-TH-IR soma area (D) in sexually naive (white) and experienced (black) animals. Data represent mean $\pm S E M$; ${ }^{*}$ indicates significant difference compared with sexually naive controls. Representative images showing TH-IR (brown) neurons in VTA of sexually naive $(\boldsymbol{E})$, and experienced $(\boldsymbol{F})$ males. $\boldsymbol{G}, \boldsymbol{H}$, A higher-magnification image of the neuron indicated by the arrow in $\boldsymbol{E}$ and $\boldsymbol{F}$ respectively. Nissl-stained neurons are shown in blue in these images. Representative images showing TH-IR neurons in SN of sexually naive $(\boldsymbol{I})$ and experienced $(\boldsymbol{J})$ males. Scale bars: $\boldsymbol{E}-\boldsymbol{J}, 20 \mu \mathrm{m}$.

0.001 ; perimeter, $\left.F_{(1,31)}=18.225, p<0.001\right)$. There was also a main significant effect of time (area: $F_{(2,31)}=6.377, p=0.005$; perimeter, $\left.F_{(2,31)}=4.389, p=0.021\right)$ and a significant interaction between experience and time (area: $F_{(2,31)}=5.284, p=0.011$; perimeter, $\left.F_{(2,31)}=4.347, p=0.022\right)$. Pairwise comparisons revealed that area and perimeter of TH-IR cells were significantly reduced 1 and $7 \mathrm{~d}$ after the last day of sexual behavior in sexually experienced animals compared with sexually naive controls [Fig. $1 B$, area: $p=0.002(1 \mathrm{~d}), p<0.001(7 \mathrm{~d})$; $C$, perimeter: $p=0.009$ (1 d), $p<0.001(7 \mathrm{~d})]$. The effect of sexual behavior dissipated when followed by the period of reward abstinence as the soma size of TH-IR neurons reverted to baseline $31 \mathrm{~d}$ after the last mating session (Fig. $1 B$, area: $p=0.798$; $C$, perimeter: $p=0.785$ ). Sex experience-induced alterations were not detected in circularity at any of the time points (Fig. 1D). VTA dopamine soma size reduction was not dependent on daily mating sessions, as mating experience during five biweekly mating sessions also produced a reduced VTA dopamine soma size (Fig. $2 A, B, E-H$, area: $p=$ 0.004; perimeter: $p<0.001)$. In contrast, sex experience did not affect TH-IR soma size in the substantia nigra (Fig. $2 C, I-J$, area: $p=0.13$; perimeter: $p=0.16$ ) nor altered soma size in nearby VTA non-TH-IR neurons (Fig. $2 D, E-H$, area: $p=0.46$; perimeter: $p=0.45$ ).

\section{Sex experience-induced soma size reduction of VTA} dopamine neurons is dependent on opioid receptor activation The reduction of VTA dopamine neuron soma size caused by sexual experience was blocked by the nonselective MOR antagonist naloxone, administered before each mating session. Naloxone treatment before mating sessions had a significant effect on area $\left(F_{(1,22)}=4.738, p=0.041\right)$ and trended toward a significant effect on perimeter $\left(F_{(1,22)}=2.892, p=0.052\right)$. A significant interaction between experience and naloxone treatment was found for area $\left(F_{(1,22)}=5.578, p=0.027\right)$ and perimeter $\left(F_{(1,22)}\right.$ $=8.167, p=0.009)$. Pairwise comparisons showed that sexual experience in saline-treated animals significantly reduced area and perimeter of VTA dopamine neurons $7 \mathrm{~d}$ after the last mating session compared with saline-treated sexually naive males (Fig. $1 E$, area: $p=0.018 ; F$, perimeter: $p=0.007)$. In contrast, sexually experienced naloxone-treated animals did not differ from naloxone-treated naive males (Fig. $1 E$, area: $p=0.483$; $F$, perimeter: $p=0.330)$. In addition, the soma size of experienced saline animals was significantly decreased compared with experienced naloxone animals (Fig. $1 E$, area: $p=0.002 ; F$, perimeter: $p=$ 0.002 ). This effect of naloxone was specific for sexual experience, as naloxone treatment alone did not affect TH-IR cell soma size in sexually naive naloxone-treated males compared with salinetreated controls (Fig. 1E,F). Moreover, this effect of naloxone on experience-induced soma size reduction was not due to effects of naloxone on sexual behavior, as mating behavior did not significantly differ between naloxone- and saline-treated males, except for a longer time to initiate mating after ejaculation (post ejaculation interval) in naloxone-treated males during the first and fifth mating session ( $p=0.03$ and $p=0.004$, respectively). Both saline- and naloxone-treated males copulated to ejaculation during each of the five mating sessions.

\section{Sexual experience-induced morphine reward tolerance}

The effects of sexual experience on VTA dopamine soma size by the action of EOP in the VTA are similar to those reported for exogenous opiates (Sklair-Tavron et al., 1996; Russo et al., 2007). Therefore, it was tested whether natural reward-induced VTA dopamine cell plasticity affects reward for the opiate morphine. Indeed, sexual experience caused morphine reward tolerance, similar to the effects of chronic opiates (Russo et al., 2007). Sexually experienced males failed to develop a CPP for $0.5 \mathrm{mg} / \mathrm{kg}$ morphine dose; whereas, sexually naive males did form a CPP for this dose, as indicated by spending a greater amount of time in the morphine-paired chamber compared with the saline-paired chamber during the post-test (Fig. $3 ; p=0.039$ ). Both sexually 
naive and experienced groups spent a significantly greater amount of time in the morphine-paired chamber compared with the saline-paired chamber with higher doses of morphine: 5.0 $\mathrm{mg} / \mathrm{kg}$ (Fig. 3 ; Naïve: $p=0.029$; Exp: $p=0.012$ ) and $10.0 \mathrm{mg} / \mathrm{kg}$ (Fig. 3; Naïve: $p<0.001$; Exp: $p=0.002$ ).

\section{Sex experience-induced facilitation of mating behavior is dependent on opioid receptor activation}

The findings thus far demonstrate that EOP acting in the VTA during 5 daily short mating sessions cause plasticity of the VTA dopamine neurons that is similar to the effects of chronic morphine or heroin self-administration (Russo et al., 2007; MazeiRobison et al., 2011). We hypothesized that VTA dopamine soma-size reduction is critical for reward learning and specifically for sex experience-induced facilitation of sex behavior in terms of motivation and performance. This hypothesis was tested by blocking MOR using naloxone during mating and examining the effects on facilitation of sexual behavior induced by sexual experience during the five daily mating sessions. Data are presented in Figure 4 for the first and fifth mating sessions only, as these are the data that best illustrate experience-induced facilitation of mating behavior. Moreover, the longer-term effects of naloxone treatment during the mating sessions are tested on the maintenance of experience-induced facilitation of mating behavior, during a final mating test 1 week later. Figure $4 A$ shows the experimental design. There was a significant main effect of mating session on all parameters of sex behavior (mount latency: $F_{(2,55)}=11.286, p<$ 0.001 ; intromission latency: $F_{(2,55)}=8.767, p<0.001$; ejaculation latency: $\left.F_{(2,55)}=10.368, p<0.001\right)$ and naloxone treatment on latencies to mount $\left(F_{(1,55)}=6.585, p=0.013\right)$ and intromission $\left(F_{(1,55)}=7.863, p=0.007\right)$. Pairwise comparisons showed that naloxone treatment affected sexual behavior during the first mating session because naloxone animals had significantly longer latencies to first mount $(p=0.002)$ and intromission $(p=0.002)$ compared with saline controls on the first day of mating. This naloxone effect on initial sex behavior was abated by sexual experience and not observed during any of the subsequent mating sessions (Table 1). Moreover, naloxone administration before each of five mating sessions did not prevent initial facilitation of sexual behavior with sexual experience. Consistent with the reinforcing effects of sexual experience, saline-treated males exhibited decreased latencies to mount (Fig. $4 B ; p=0.032$ ) intromission (Fig. $4 C ; p=0.033$ ) and ejaculation (Fig. $4 D ; p<0.001$ ) during the fifth mating session compared with the first mating session, which indicated facilitation of sexual behavior. Similarly, naloxone-treated males displayed significantly shorter latencies to mount (Fig. $4 B ; p<0.001$ ), intromission (Fig. $4 C ; p<0.001$ ), and ejaculation (Fig. $4 D ; p=0.017$ ) on the fifth compared with the first day. Moreover, naloxone-treated males did not differ from saline controls in any of the latencies during the fifth mating session.

In contrast, naloxone treatment during sexual experience session did disrupt the maintenance of experience-induced facilitation of sexual behavior on the final mating test day. The test day was conducted $7 \mathrm{~d}$ after final mating session in the absence of a naloxone injection. Saline-treated control males displayed the expected experience-induced facilitation of sexual behavior. Specifically, latencies to mount, intromission, and ejaculation did not differ between the fifth mating session and final test day (Fig. $4 B-D)$. Whereas, naloxone-treated males showed a significant increase in latencies to mount (Fig. $4 B ; p=0.033$ ), intromission (Fig. $4 C ; p=0.036$ ) and ejaculation (Fig. $4 D ; p=0.049$ ) on the test day compared with the fifth mating session. Also, on the test day naloxone animals were found to be significantly slower than

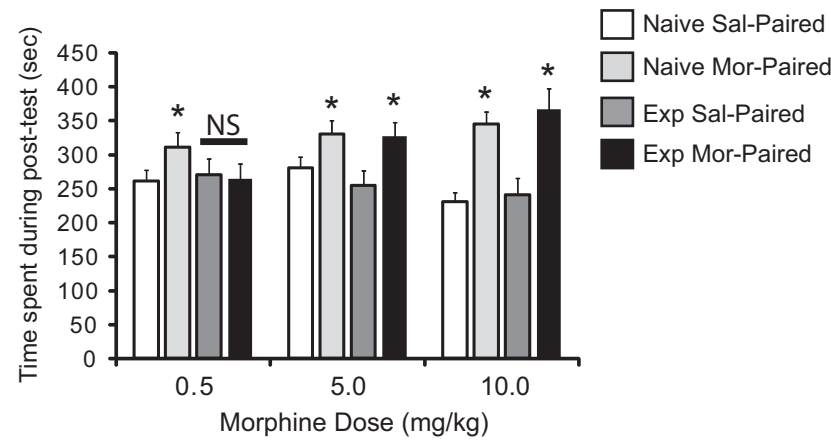

Figure 3. The effects of sexual experience on morphine reward. Times spent in saline- (Sal) or morphine- paired (Mor; $0.5,5$ or $10 \mathrm{mg} / \mathrm{kg}$ bodyweight) chambers during the post-test in sexually naive (Naive, $n=10-13$ ) or experienced (Exp, $n=9-13$ ) males. Data presented as mean $\pm S E M ; ~ *$ indicates significant difference compared with Sal-paired chamber within same animals. NS, Not significant.

saline-treated males as displayed by longer latencies to mount (Fig. $4 B ; p=0.017$ ) and intromission (Fig. $4 C ; p=0.043$ ). Thus, naloxone treatment blocked the maintenance, but not the initial, development of experience-induced facilitation of sexual behavior. These findings indicate a critical role for EOP-induced VTA dopamine neuron plasticity on long-term expression of reinforcement of natural reward behavior.

Several additional control experiments were conducted to determine that the effects of opioid receptor blockade on loss of long-term reinforcement of sexual behavior occurred independent from a lack of naloxone administration on the final mating test day (Fig. $5 A, B$ ), were specific to loss of long-term, but not short term maintenance of mating facilitation (Fig. $5 E, F$ ), were not caused by daily exposure to naloxone alone (Fig. $5 C, D$ ), and were not caused by a loss of sexual reward in naloxone-treated males (Fig. 5G,H). First, to show that altered sexual behavior on the final mating test was not due to the absence of naloxone, either naloxone or saline was administered on the final mating test day to animals that received mating paired with naloxone while they gained sexual experience (Fig. 5A). There was a significant main effect of mating day on latencies to mount (Fig. $5 B$; $\left.F_{(2,27)}=30.031, p=0.038\right)$ and intromission (Table 2; $F_{(2,27)}=$ $10.686, p=0.048)$. There was no main effect of mating day on latency to ejaculation (Table 2; $F_{(2,27)}=2.388, p=0.109$ ) Similar to described above, naloxone treatment during mating did not affect the facilitation of sexual behavior during the initial five sexual experience sessions. Both groups (saline- and naloxonetreated groups as determined by treatment received during the final mating test; both received naloxone during mating) demonstrated facilitated sexual behavior on day 5 compared with day 1 and showed significantly shorter latencies to first mount (Fig. $5 B$; saline: $p=0.033$; naloxone: $p=0.014$ ) and intromission (Table 2 ; saline: $p=0.034$; naloxone: $p=0.026$ ). Animals that received either naloxone or saline on the final mating test day had longer latencies to mount (Fig. $5 B$; saline: $p=0.018$; naloxone: $p=$ 0.029 ) and intromission (Table 2; saline: $p=0.019$; naloxone: $p=0.020)$ compared with the fifth day of mating experience. Therefore, the administration of naloxone or saline on the test day immediately before mating did not influence the effect of naloxone treatment during sexual experience sessions and attenuation of long-term facilitation of sexual behavior was identical to that shown in animals that did not receive any injection on final mating test day (Fig. 4).

To determine whether it was naloxone treatment when paired with sexual experience and not repeated to naloxone per se that 
A
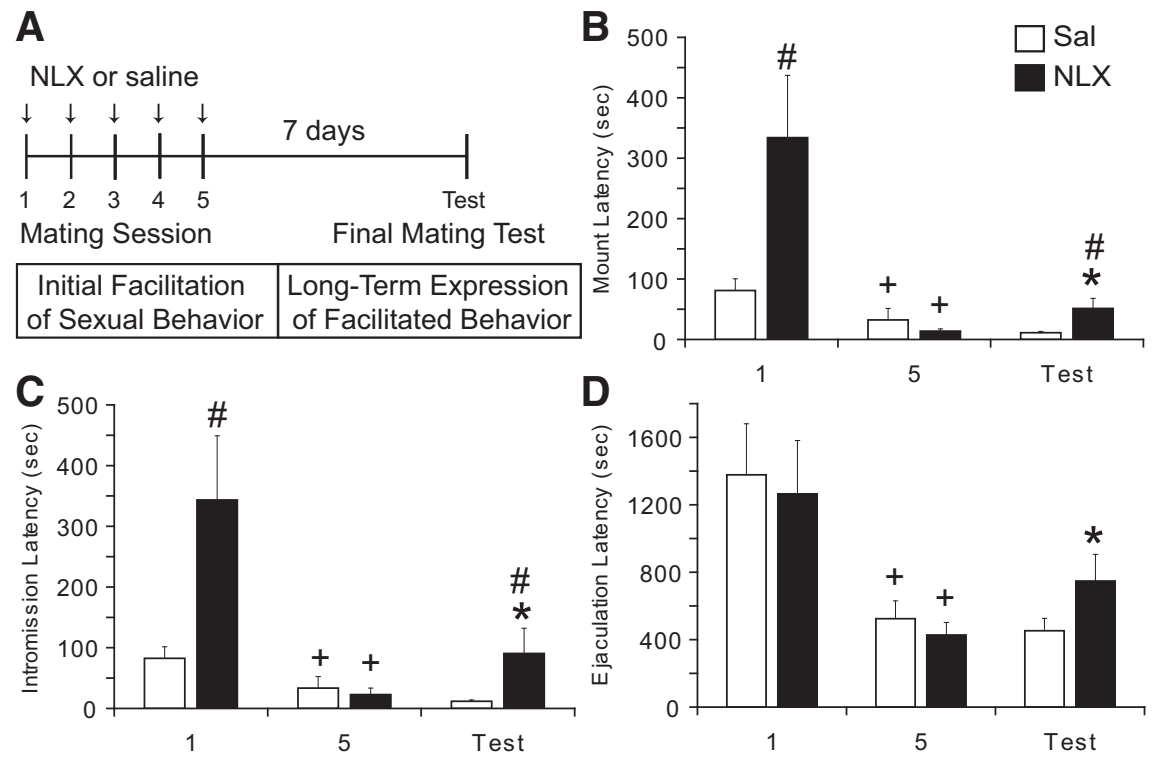

Figure 4. Endogenous opioids play a critical role in the experience-induced facilitation of sexual behavior. $\boldsymbol{A}$, Experimental design. $\boldsymbol{B}-\boldsymbol{D}$, Sexual behavior parameters for males treated with saline (Sal, white bars, $n=11$ ) or naloxone (NLX; black bars, $n=$ 12) with systemic administration. Data shown are latency to mount ( $\boldsymbol{B}$; seconds), intromission ( $\boldsymbol{C}$; seconds), and ejaculation ( $\boldsymbol{D}$; seconds) on days 1 and 5 of five consecutive days of mating. In addition, data are shown for the final mating test, $7 \mathrm{~d}$ after the fifth mating session. Data are presented as mean \pm SEM; + indicates significant difference between days 1 and 5 within treatment; * indicates significant difference between test day and day 5 within treatment; \# indicates significant difference between naloxone and saline groups within day.

Table 1. Naloxone administration prior to mating increased latencies to mount and intromission only on the first day of mating

\begin{tabular}{|c|c|c|c|c|c|c|}
\hline \multirow[b]{2}{*}{ Days } & \multicolumn{2}{|c|}{ Mount latency } & \multicolumn{2}{|c|}{ Intromission latency } & \multicolumn{2}{|c|}{ Ejaculation latency } \\
\hline & Saline & Naloxone & Saline & Naloxone & Saline & Naloxone \\
\hline 1 & $81 \pm 19$ & $334 \pm 103^{*}$ & $83 \pm 19$ & $343 \pm 106^{*}$ & $1378 \pm 303$ & $1265 \pm 317$ \\
\hline 2 & $234 \pm 117$ & $163 \pm 83$ & $301 \pm 119$ & $198 \pm 79$ & $598 \pm 79$ & $753 \pm 198$ \\
\hline 3 & $101 \pm 40$ & $186 \pm 63$ & $134 \pm 41$ & $211 \pm 68$ & $803 \pm 229$ & $753 \pm 163$ \\
\hline 4 & $110 \pm 78$ & $154 \pm 105$ & $112 \pm 79$ & $195 \pm 105$ & $490 \pm 122$ & $702 \pm 140$ \\
\hline 5 & $32 \pm 19$ & $14 \pm 4$ & $33 \pm 19$ & $23 \pm 11$ & $524 \pm 106$ & $427 \pm 75$ \\
\hline
\end{tabular}

The effect of naloxone was not observed during any of the subsequent mating sessions Data shown are latencies to intromission and ejaculation (seconds) in animals treated either with systemic (s.c.) saline or naloxone (10 mg/kg) during 5 consecutive days (saline, $n=11$; naloxone, $n=12$ ). Data for days 1 and 5 are also presented in Figure 4 . Data are presented as mean \pm SEM; * indicates significant difference between treatments on the same day.

caused impairment of sexual behavior $7 \mathrm{~d}$ after last treatment, sexually naive animals received either five daily injections of naloxone or saline injections before a final mating test $7 \mathrm{~d}$ later (Fig. $5 \mathrm{C}$ ). No significant differences were detected for any mating parameter between saline and naloxone pretreated groups (Fig. 5D; mount latency; intromission latency: saline $139.7 \pm 40.3$ vs naloxone $121.83 \pm 42.55$; ejaculation latency: saline $887.9 \pm 70.0$ vs naloxone $1050.8 \pm 327.31)$. These results indicate that naloxone alone is not sufficient to alter subsequent sexual behavior, similar to the lack of effects of naloxone alone on VTA dopamine neuron plasticity.

We hypothesize that naloxone treatment during the acquisition of sexual experience disrupts the long-term expression of sex experience-induced facilitation of sexual behavior. To test this further, the effects of naloxone treatment during mating were tested on subsequent sexual behavior during a final mating test, which was conducted only $1 \mathrm{~d}$ after last mating (experimental design; Fig. $5 E$ ). There was a significant main effect of mating day on mount (Fig. 5F; $\left.F_{(2,20)}=19.780, p<0.001\right)$ and intromission latencies (Table $2 ; F_{(2,20)}=19.041, p<0.001$ ). There was no significant main effect of day on ejaculation latency (Table 2; $\left.F_{(2,20)}=3.042, p=0.070\right)$. Similar to described above, all males (despite the saline or naloxone treatments) showed facilitation of sexual behavior during the five sexual experience sessions indicated by significantly shorter latencies to mount (Fig. $5 F$; saline: $p=$ 0.002; naloxone: $p=0.018$ ) and intromission (Table 2; saline: $p=0.006$; naloxone: $p=0.009)$ on day 5 compared with day 1 . Similarly, facilitated sexual behavior was demonstrated on test day compared with day 1 indicated by significantly shorter latencies to mount (Fig. $5 F$; saline: $p=$ 0.001 ; naloxone: $p=0.020$ ) and intromission (Table 2; saline: $p=0.004$; naloxone: $p=0.009$ ). More importantly, naloxone treatment during mating did not significantly affect the sex experience-induced facilitation of sex behavior when tested $1 \mathrm{~d}$ after sex experience, independent of naloxone treatment on this final mating test day.

Finally, we tested the possibility that naloxone's attenuating effects on the long-term expression of facilitated sexual behavior is due to a blocking effect of naloxone on the rewarding properties of sexual behavior. However, naloxone administered immediately before mating did not alter formation of CPP for mating (Fig. 5G), suggesting that naloxone treatment did not alter sexual reward. Both saline- and naloxone-treated groups formed a significant CPP for sexual behavior as indicated by significantly increased time spent in sex-paired chamber (Fig. $5 H$; saline: $p=$ 0.038; naloxone: $p=0.002$ ) during the post-test compared with the pretest. Therefore, naloxone does not exert its detrimental effect on maintenance of facilitated sexual behavior by blocking the reward associated with sexual behavior.

\section{Facilitation of sexual behavior is dependent on EOP action in the VTA}

To confirm that EOP act specifically in the VTA to induce longterm facilitation of sexual behavior, the experimental design outlined in Figure $3 A$ was repeated with intra-VTA naloxone infusions rather than systemic injections. Results were identical to systemic administration described above. There was a significant main effect of mating day on all parameters of sex behavior (Fig. $6 A$, mount latency: $F_{(2,33)}=4.494, p=0.019 ; B$, intromission latency: $F_{(2,33)}=4.042, p=0.027 ; C$, ejaculation latency: $\left.F_{(2,33)}=5.309, p=0.010\right)$ and intra-VTA naloxone treatment on latencies to mount $\left(F_{(1,33)}=7.345, p=0.011\right)$ and intromission $\left(F_{(1,33)}=6.126, p=0.019\right)$. Intra-VTA naloxone did not prevent the initial experience-induced facilitation of sexual behavior during the $5 \mathrm{~d}$ of mating, as naloxone-treated males demonstrated decreased latencies to mount (Fig. $6 A ; p=0.001$ ), intromission (Fig. $6 B ; p<0.001$ ), and ejaculation (Fig. $6 C ; p=0.001$ ) on day 5 compared with day 1 . Naloxone-treated males did not differ from saline-treated males on the fifth day of mating in any of the latencies. Intra-VTA naloxone treatment, like systemic administration, caused significantly increased mount (Fig. 6A; $p<0.001$ ) and intromission latencies (Fig. $6 B ; p<0.001$ ) on the first mating day compared with saline-treated males, which was not observed during subsequent mating sessions (during which naloxone- and saline-treated males did not differ). One unexpected observation 
was that in this experiment, saline-treated males did not show statistically significant facilitation of mount or intromission latencies (as was shown in all experiments described above), and only ejaculation latency was shorted on the fifth day compared with the first day (saline: $p=0.001$ ).

Intra-VTA naxolone treatment blocked the maintenance of facilitated sexual behavior observed in sexually experienced males, similar to the effects of systemic naloxone. Specifically, on the final test day naloxone-treated males had longer latencies to mount (Fig. $6 A ; p=0.011$ ), intromission (Fig. $6 B ; p=0.010$ ), and ejaculation (Fig. $6 C ; p=0.015$ ) compared with their fifth mating session and compared with the saline-treated males on the final test day (Fig. $6 A, p=0.006 ; B, p=$ $0.008)$. In contrast, saline-treated animals did not differ in latencies to mount and intromission between the final test day and day 5 of mating. These effects were specific to delivery of naloxone to the VTA, as males with cannulation sites nearby but not targeting the VTA (Fig. $6 \mathrm{D} ; n=3$ ) displayed long-term facilitation of sexual behavior similar to salinetreated controls $(\mathrm{ML}, \mathrm{IL}=53 \pm 6.245$, $\mathrm{EL}=389 \pm 299.5$ and significantly different compared with intra-VTA naloxone animals on the final mating test day (ML, IL: $p=0.029$; EL: $p=0.0395$ ).

\section{EOP action is required for sex-} associated conditioned cue-induced neural activation

Based on the findings thus far, we hypothesized that EOP activation in VTA during mating experience and subsequent VTA dopamine soma size reduction are critical for the attribution of incentive salience to mating reward-associated stimuli and consequently, the maintenance of facilitated of sexual behavior. To test this hypothesis, the effects of blocking opioid receptors during mating experience on neural activity induced by subsequent exposure to conditioned contextual cues predictive of sexual reward (sexassociated contextual cues) were examined. Sexually naive animals were also exposed to environmental cues, but these were not associated with previous mating experience, hence were neutral cues. Finally, baseline pERK levels were determined in sexually experienced and naive control groups that remained in the home cages and not exposed to any cues (-No Cue). Confirming and expanding previous findings (Balfour et al., 2004), exposure to contextual cues associated with previous sex reward significantly in-

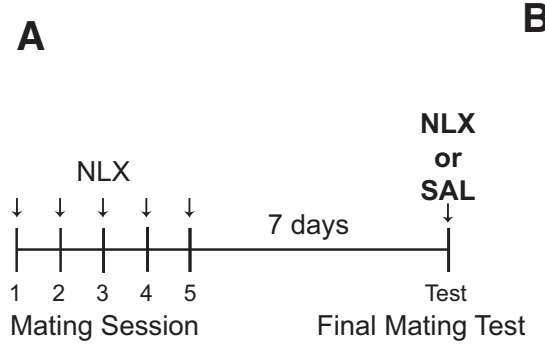

B
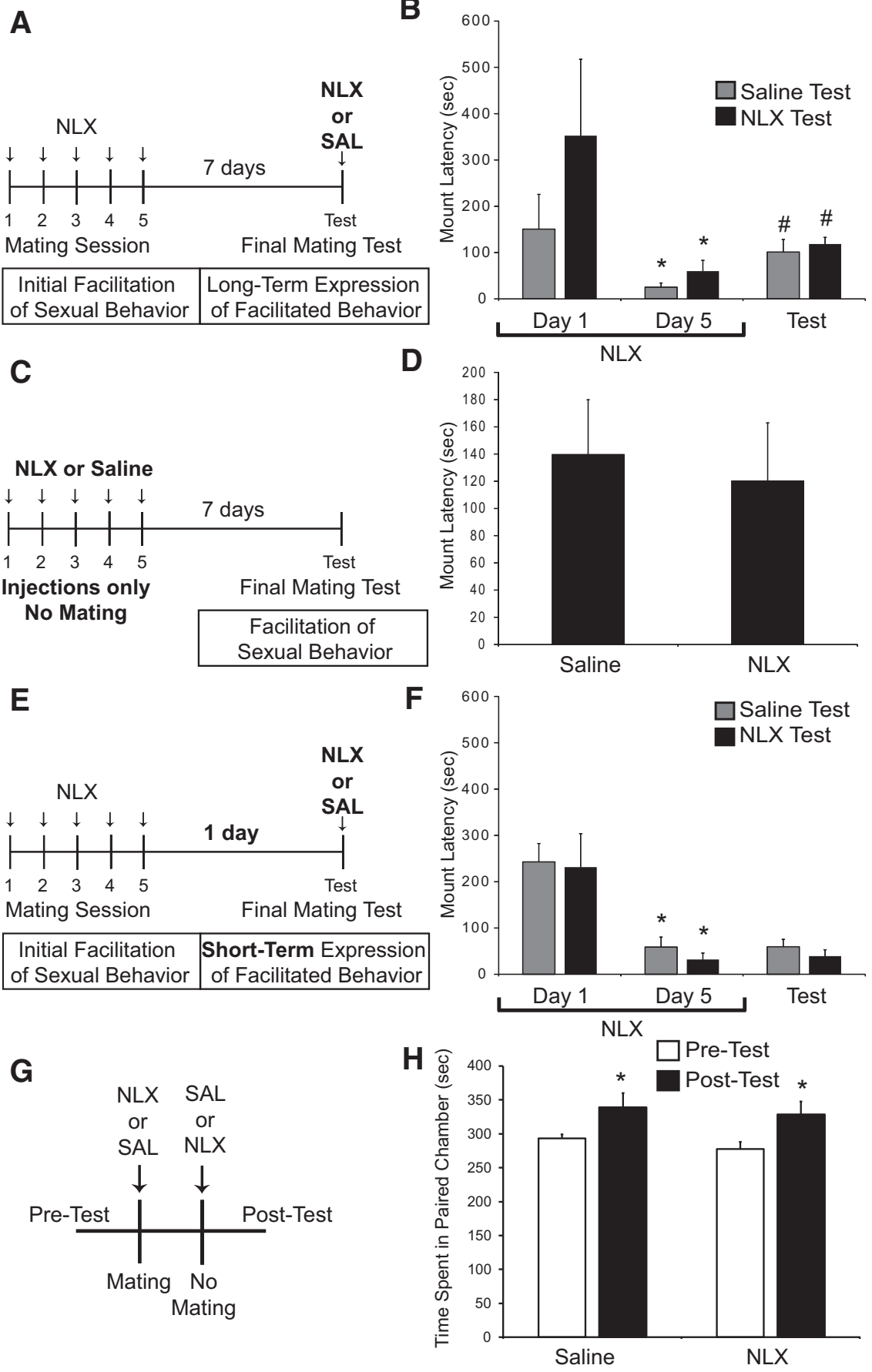

Figure 5. Endogenous opioids are important in the long-term expression of experience-induced facilitation of sexual behavior. $\boldsymbol{A}$, Experimental design for experiment to the effect of NLX treatment on test day. $\boldsymbol{B}$, Mount latency on days 1 and 5 of five consecutive days of mating and final mating test day (Test) following saline (gray) or naloxone (black) injection. Data represent mean \pm SEM. ${ }^{*}$ indicates significant difference between day 1 and day 5 within treatment. \# indicates significant difference between Test day and Day 5 within treatment. $C$, Experimental design for experiment to test the effect of naloxone pre-treatment alone without sexual experience on mating behavior. $\boldsymbol{D}$, Mount latency on final mating test day, 7 days following 5 days of either saline or naloxone injection in the absence of mating. Data represent mean \pm SEM. $\boldsymbol{E}$, Experimental design for experiment to test whether naloxone treatment affected the short-term display of facilitated sexual behavior in sexually experienced animals. $\boldsymbol{F}$, Mount latency on day 1 and day 5 of five consecutive days of mating and final mating test day, 1 day after day 5 in the presence of saline (grey) or naloxone (black) injection. Data represent mean \pm SEM. ${ }^{*}$ indicates significant difference between day 1 and day 5 within treatment. $\mathbf{G}$, Experimental design for experiment to test whether naloxone treatment blocked the rewarding effects of sexual behavior. $\boldsymbol{H}$, Time spent in mating paired chamber (in seconds) during the pretest (white) and post-test (black) for animals receiving either naloxone or saline before mating. Data represent mean $\pm S E M$; * indicates significant difference compared with pretest. 
Table 2. Data shown are latencies to intromission and ejaculation (seconds) from control experiments conducted to determine that the effects of MOR blockade on loss of long-term reinforcement of sexual behavior occurred independent from a lack of naloxone administration on the final mating test day

\begin{tabular}{|c|c|c|c|c|c|}
\hline \multirow[b]{2}{*}{ Experiment } & \multirow[b]{2}{*}{ Day } & \multicolumn{2}{|c|}{ Saline during final mating test } & \multicolumn{2}{|c|}{ Naloxone during final mating test } \\
\hline & & Intromission latency & Ejaculation latency & Intromission latency & Ejaculation latency \\
\hline NLX or saline administration on & 1 & $157.7 \pm 75.0$ & $707.0 \pm 501.1$ & $345.6 \pm 139.4$ & $645.7 \pm 124.8$ \\
\hline final mating test day: $7 \mathrm{~d}$ after & 5 & $25.8 \pm 8.9^{*}$ & $341.3 \pm 83.5$ & $74.6 \pm 22.5^{*}$ & $404.7 \pm 83.19$ \\
\hline mating experience (Fig. 5A) & Test & $101.2 \pm 27.1 \#$ & $580.2 \pm 151.0$ & $161.9 \pm 35.1 \#$ & $711.3 \pm 136.9$ \\
\hline NLX or saline administration on & 1 & $394.3 \pm 110$ & $748.3 \pm 243$ & $161.5 \pm 58.2$ & $286.5 \pm 66.8$ \\
\hline final mating test day: $1 \mathrm{~d}$ after & 5 & $61.6 \pm 22.0^{*}$ & $418.0 \pm 150$ & $38.3 \pm 16.4^{*}$ & $365.25 \pm 77.9$ \\
\hline mating experience (Fig. 5E) & Test & $60.8 \pm 15.5^{*}$ & $265.2 \pm 37.8$ & $39.3 \pm 13.7^{*}$ & $340.5 \pm 73.1$ \\
\hline
\end{tabular}

Data presented are for behavior on days 1 and 5 of five consecutive days of mating and the final mating test, either $1 \mathrm{~d}$ (saline, $n=5 ;$ naloxone, $n=4$ ) or $7 \mathrm{~d}$ (saline, $n=6$; naloxone, $n=7$ ) after the fifth mating session. Data are presented as mean \pm SEM; ${ }^{*}$ indicates significant difference compared with day 1 within treatment; \# indicates significant difference between test day and day 5 within treatment.

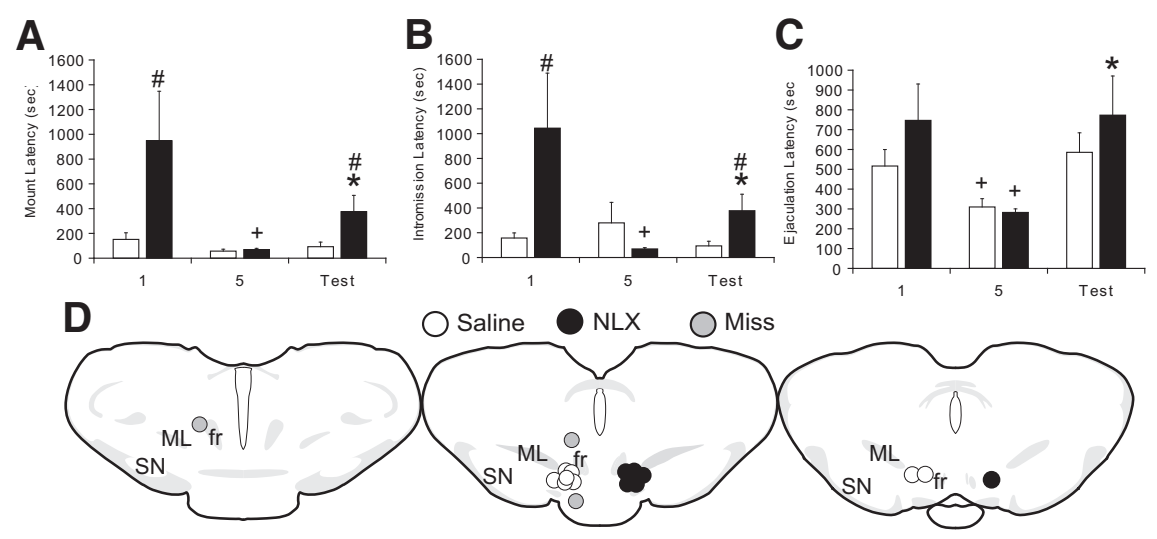

Figure 6. Endogenous opioids in the VTA mediate experience-induced facilitation of sexual behavior and its long-term maintenance. Sexual behavior parameters for males treated with saline (Sal, white bars, $n=8$ ) or NLX (black bars, $n=6$ ) with intra-VTA administration. Data shown are latency to mount $(\boldsymbol{A})$, intromission $(\boldsymbol{B})$, and ejaculation $(\boldsymbol{C})$ on days 1 and 5 of five consecutive days of mating. In addition, data are shown for the final mating test day, $7 \mathrm{~d}$ following day 5 in the absence of saline or naloxone injection. Data represent mean \pm SEM; + indicates significant difference between days 1 and 5 within treatment; * indicates significant difference between test day and day 5 within treatment; \# indicates significant difference between naloxone and Sal groups within day. Schematic drawings of coronal VTA sections $(\mathrm{H},-4.60 ; \mathrm{I},-5.00 ; \mathrm{J},-5.25$ from bregma) indicating intra-VTA injection sites for all animals in Experiment 5 (saline; white; naloxone, black; Missed, gray), using template drawings from Swanson Brain Maps (Swanson, 2004). Cannulas were bilateral, but injection sites are represented unilaterally for ease of presentation. fr, Fasciculus retroflexus; ML, Medial lemniscus; SN, substantia nigra.

creased pERK expression in sexually experienced males in the NAc (Fig. 7) and mPFC (Fig. 8A-C), but did not cause neuronal activation in the BLA (Fig. $8 D$ ) or $\mathrm{CPu}$ (data not shown). There were main effects of cue exposure in NAc core $\left(F_{(1,12)}=12.1941\right.$, $p=0.004), \operatorname{ACA}\left(F_{(1,12)}=5.541, p=0.038\right)$, and PL $\left(F_{(1,12)}=\right.$ 5.241, $p=0.041)$, and naloxone treatment in in the NAc core $\left(F_{(1,12)}=6.511, p=0.025\right), \operatorname{ACA}\left(F_{(1,12)}=15.242, p=0.002\right)$, and $\operatorname{PL}\left(F_{(1,12)}=7.336, p=0.019\right)$. There was significant interaction in the NAc core $\left(F_{(1,12)}=10.107, p=0.008\right), \operatorname{ACA}\left(F_{(1,12)}\right.$ $=16.060, p=0.002), \mathrm{PL}\left(F_{(1,12)}=8.235, p=0.014\right)$, and IL $\left(\left(F_{(1,12)}=6.965, p=0.022\right)\right.$. First, mating-associated Cue exposure significantly increased pERK in saline-treated sexually experienced animals (Exp Sal+Cue) compared with controls that were not exposed to any cues and taken from the home cage (Exp Sal-No Cue) in NAc core (Fig. 7A; $p<0.001$ ), and mPFC subregions ACA (Fig. 8A; $p=0.001$ ), PL (Fig. $8 B ; p=0.003$ ), and IL (Fig. $8 C ; p=0.029$ ). In contrast, in saline-treated sexually naive animals, exposure to the contextual cues, which were not associated with sexual reward, did not induce pERK in any of the brain areas (Naive Sal+Cue compared with naive Sal-No Cue; Figs. 7, 8 ), demonstrating that induction of pERK is specific to the exposure of the sexual experience-associated cues. Moreover, sexual experience alone did not alter baseline pERK expression in any of the brain regions, as there were no differences between groups that were taken from the home cages, whether sexually naive or experience, and treated with saline or naloxone.

In support of our hypothesis, naloxone treatment during sexual experience significantly attenuated pERK induction by the sex-associated conditioned cues. pERK expression in these naloxone-treated cueexposed experienced males (Exp NLX+Cue) did not differ from baseline pERK expression in any of the sexually naive or experienced control groups taken from the home cages (Naive Sal-No Cue or Naive NLX-No Cue). Moreover, pERK expression in the naloxone-treated cue-exposed experienced males (Exp NLX+Cue) was significantly lower compared with salinetreated cue-exposed experienced animals (Exp Sal+Cue) in NAc core (Fig. $7 A ; p=$ 0.002 ) and mPFC subregions (Fig. $8 A$, ACA: $p<0.001 ; B$, PL: $p=0.002 ; C$, IL: $p=0.015)$.

In the NAc shell, the two-way ANOVA analysis did not yield statistically significant effects of the factors cue exposure and naloxone treatment. However, a pairwise comparison showed that cue exposure did induce pERK in the saline-treated sexually experienced group (Exp SAL+Cue) compared with the no cue-exposed Saline naive control group (Fig. 7B; Naive SAL-No Cue: $p=0.0163$ ).

\section{Discussion}

The current study demonstrates that EOP acting in the VTA during sexual behavior, a natural reward behavior, caused a robust but transient reduction in soma size of VTA dopamine cells. The reduction in soma size was not observed in VTA non-dopamine neurons, nor in dopamine neurons in the nearby substantia nigra, suggesting this change was specific to VTA dopamine cells. This VTA dopamine plasticity appears similar to that induced by chronic opiate exposure (Sklair-Tavron et al., 1996; Russo et al., 2007; Mazei-Robison et al., 2011) and caused similar tolerance to exogenous opiate (morphine) reward. We demonstrated that VTA dopamine plasticity is critical for the long-term (maintenance) but not short-term (development), reinforcement of sexual behavior and reward-associated cueinduced neural activity (pERK) in VTA target regions: NAc and mPFC. These findings are indicative of a role for VTA dopamine plasticity in the long-term expression of the incentive salience of natural reward predictive cues or reward memory.

It has been well documented that sexual experience results in facilitation of subsequent sexual behavior, including faster onset 

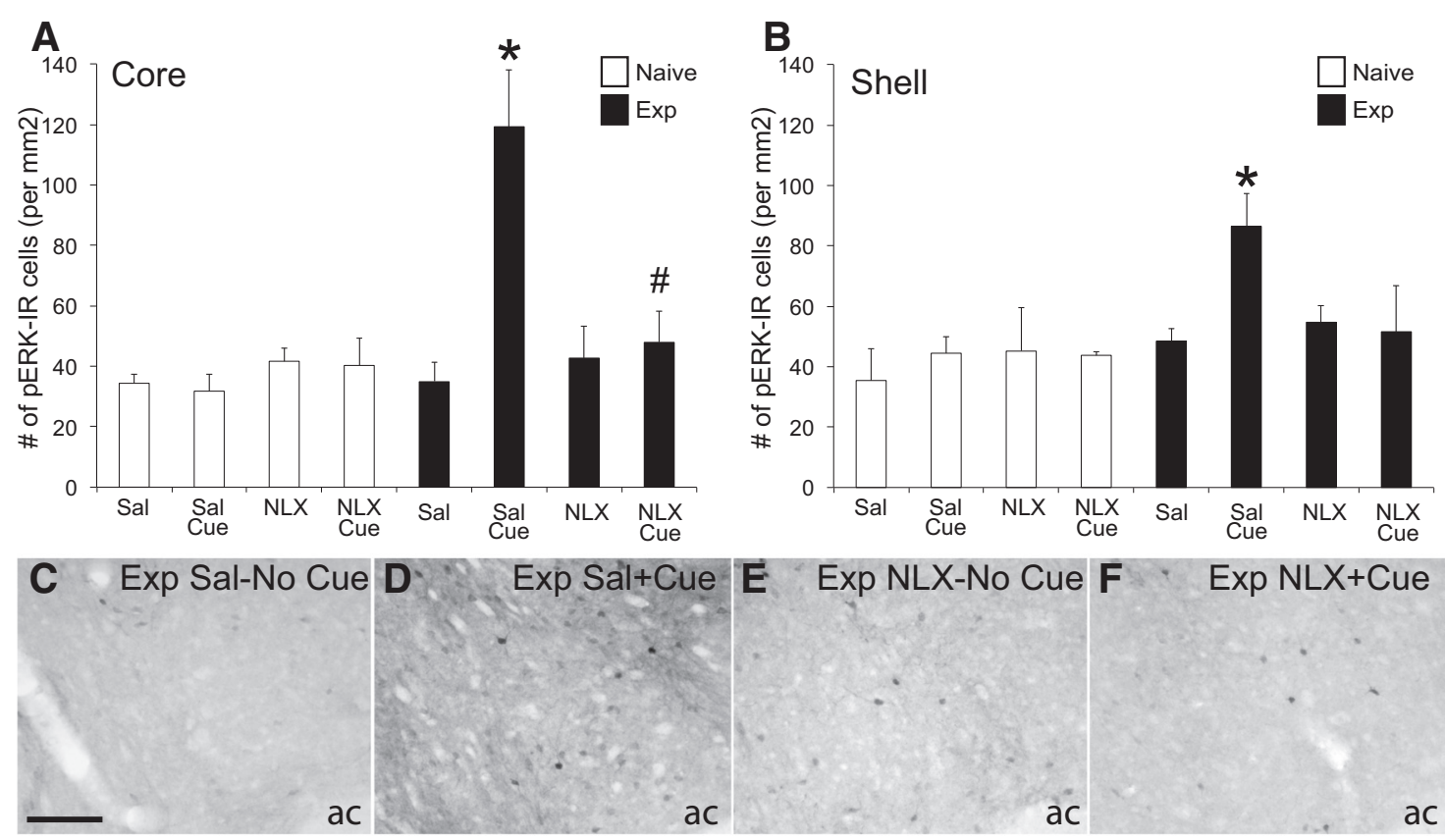

Figure 7. Endogenous opioid action is required for neural activation in NAc induced by sex-associated conditioned cues. Numbers of pERK-IR cells per mm ${ }^{2}$ in the nucleus accumbens core $(\boldsymbol{A})$ and shell (B) in sexually naive (white) and experienced (Exp; black) animals that were pretreated with systemic NLX or saline (Sal) during mating sessions (Exp males) or handling sessions (Naive males). Groups were either exposed to contextual cues (Cue), which were mating-associated cues in Exp males and neutral cues in Naive animals, or taken from the home cages (No Cue; indicated by lack of Cue-label). Data are presented as mean \pm SEM; * indicates significant difference compared with saline-pretreated no cue-exposed controls (Naive Sal-No Cue and Exp Sal-No Cue); \# indicates significant difference compared with Sal-treated Cue-exposed Exp group (Exp Sal + Cue). Representative images of pERK-IR cells per mm ${ }^{2}$ in the NAc core of sexually experienced males with Sal ( $\boldsymbol{C}$, D) or NLX $(\boldsymbol{E}, \boldsymbol{F})$ that were either taken from the home cage (No Cue, C, E), or exposed to the mating-associated contextual cues (Cue; $\boldsymbol{D}, \boldsymbol{F})$. $N=4$ each group except Naive NLX (No Cue), $n=3$. ac, Anterior commissure. Scale bar, $100 \mu \mathrm{m}$.

A
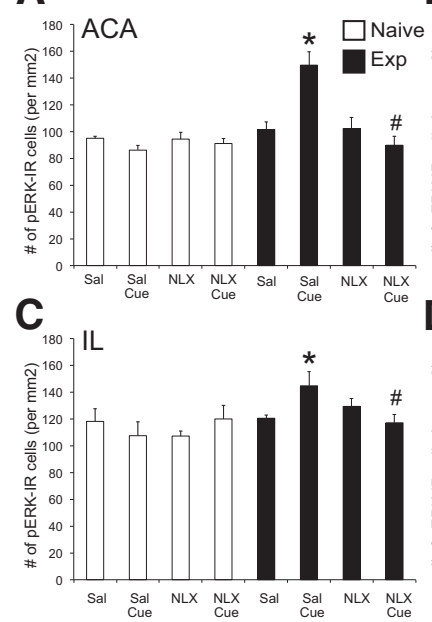

B
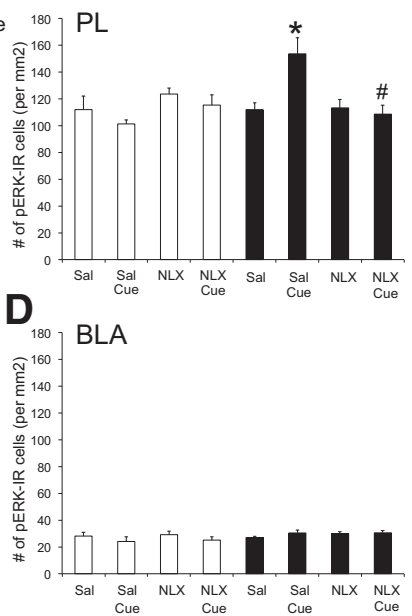

Figure 8. The effects of naloxone on mating cue-induced pERK expression in other VTA target regions. Numbers of pERK-IR cells per $\mathrm{mm}^{2}$ in sexually naive (white) and experienced (Exp; black) animals that were pretreated with systemic NLX or saline (Sal) during mating sessions and were exposed to the contextual cues (Cue) or home cage (no cues) in the ACA (A), $\mathrm{PL}(\boldsymbol{B})$, IL (C), and BLA (D). Data are represent mean \pm SEM; * indicates significant difference compared with saline-pretreated no cue-exposed controls (Naive Sal-No Cue and Exp Sal-No (ue); \# indicates significant difference compared with Sal-treated cue-exposed sexually naive controls (Naive Sal+Cue).

to initiation of mating and increased performance (Balfour et al., 2004; Pitchers et al., 2010a,b, 2012). This facilitation or reinforcement of sexual behavior is maintained for at least $28 \mathrm{~d}$ after mating (Pitchers et al., 2012). In addition, it has been shown that sex behavior and conditioned cues predictive of sex reward cause
MOR internalization in the VTA and induce neuronal activation throughout the mesolimbic system, including in VTA (dopamine and nondopamine neurons), NAc, PFC, and BLA (Balfour et al., 2004, 2006). It is well established VTA dopamine neurons play a critical role in the learning and attribution of the incentive salience of reward-associated stimuli (Berridge and Robinson, 1998; Berridge et al., 2009; Flagel et al., 2011) and are critical for reward prediction (Schultz, 2010). The current findings expand on our current knowledge by demonstrating that rewardinduced VTA neuroplasticity is critical for these functions, and is dependent on MOR activation by EOP in the VTA. It is currently unknown which EOP is the MOR ligand that acts in the VTA during male sexual behavior. Although both $\beta$ endorphin and enkephalin have been implicated in incentive motivation for food reinforcers (Hayward et al., 2002), this remains to be established for male sexual behavior. We have previously shown that $\beta$-endorphin neurons are not activated during mating, nor are there increases in POMC mRNA; thus, suggesting that $\beta$ endorphin may not be the critical EOP acting in the VTA during mating (Davis et al., 2007). This VTA dopamine plasticity was essential for neural activity in the mPFC, NAc, and VTA following exposure to the sexual reward-predicting environmental cues. Moreover, VTA dopamine plasticity was critical for the long-term expression of increased initiation and performance of sexual behavior. In contrast, VTA neuroplasticity caused by sexual experience was not required for hedonic response as sex reward (determined by CPP) and short-term facilitation of sexual motivation and performance (during sex experience or $1 \mathrm{~d}$ later) remained intact despite MOR blockade during mating (Mehrara and Baum, 1990). Instead, the data suggest that VTA dopamine neuroplasticity mediates the longer term (7 d after last sex experience; Pitchers et al., 2012) expression of "wanting" of sex re- 
ward and heightened motivated responses to mating cues (Miller and Baum, 1987; Berridge and Robinson, 1998).

Sexually experienced animals demonstrated cross-tolerance to morphine reward, similar to the effects of wheel running in mice, another natural rewarding behavior, an effect blocked with naloxone treatment (Lett et al., 2001, 2002) and determined to be dependent on VTA dopamine cell plasticity (current findings). Similar to natural rewards, repeated exposure to the opiates morphine or heroin results in a transient reduction of VTA dopamine soma size (Sklair-Tavron et al., 1996; Spiga et al., 2003; Russo et al., 2007; Mazei-Robison et al., 2011). Moreover, opiate exposure with short withdrawal periods causes reward tolerance, as implicated by higher doses of drug being required to form reward associations (Shippenberg et al., 1987; Russo et al., 2007), and causes self-administering animals to escalate drug intake (Ahmed et al., 2000; Walker et al., 2003). Hence, EOP and opiates act on common neural substrates to induce reward tolerance during early withdrawal, which might reflect a compensatory homeostatic mechanism to counteract stimulation by repeated exposure (Koob and Le Moal, 2005). In contrast, during long-term opiate drug abstinence, tolerance is reversed to a sensitivity to the rewarding properties to the drug (Harris and Aston-Jones, 2003; Aston-Jones and Harris, 2004; Harris and Gewirtz, 2004). Interestingly, sexual experience followed by a sex abstinence period of 7-28 d has been found to cause cross-sensitization for psychostimulant reward (Pitchers et al., 2010a), which is dependent on mating-induced deltaFosB expression and dopamine receptor 1 activation in the NAc (Pitchers et al., 2013). Hence, sexual reward experience causes simultaneous opiate reward tolerance and psychostimulant reward sensitization, although a longer sex abstinence period on morphine reward tolerance remains to be tested. We posit that these opposite effects on drug reward may be mediated by different forms of neural plasticity in the different areas of the mesolimbic system: VTA EOP action and dopamine plasticity mediate the opiate reward tolerance (current study), whereas NAc deltaFosB expression controls psychostimulant sensitization (Pitchers et al., 2013). Both of these events can contribute to escalations of drug take (Ahmed and Koob, 1998, 1999; Ahmed et al., 2000, 2002, 2003; Walker et al., 2003).

The molecular mechanisms by which EOP influence the VTA dopamine neurons during natural reward behavior remain unknown. The IRS2-Akt-mTORC2 pathway is a major mediator of decreased soma size in the VTA caused by repeated morphine (Jaworski et al., 2005; Russo et al., 2007; Mazei-Robison et al., 2011). Repeated morphine administration induced changes in the size of dopamine neurons in the VTA can be prevented by intra-VTA infusions of brain-derived neurotrophic factor (BDNF; Sklair-Tavron and Nestler, 1995). BDNF activates this pathway through TrkB signaling (Russo et al., 2007), a receptor kinase with high affinity for BDNF and part of the IRS2-Akt pathway (Seroogy and Gall, 1993; Numan and Seroogy, 1999), and expressed on dopamine and GABA neurons in the VTA. Downregulation of the various components of the IRS2-Akt pathway using viral vector gene transfer technology mimics the effects of chronic opiate exposure. Furthermore, the effects of opiate exposure can be rescued by restoring this signaling pathway (Russo et al., 2007) and overexpression of a component of mTORC2 prevents morphine-induced VTA dopamine soma reduction (Mazei-Robison et al., 2011). Therefore, previous work investigating the effects of chronic opiates on VTA dopamine soma size shows that morphine-induced downregulation of the IRS2-Akt-mTOR pathway is both sufficient and necessary for this effect (Mazei-Robison and Nestler, 2012). Thus, it is tempting to speculate that the effects of sexual experience on VTA dopamine neuroplasticity are similarly mediated by BDNF and the IRS2Akt-mTORC2 pathway.

In conclusion, the current study demonstrated that VTA neuroplasticity is caused by experience with natural rewarding behavior, in particular by repeated male sexual behavior. Specifically, EOP act in the VTA to reduce dopamine soma size, which is hypothesized to be associated with increased neural excitability and less dopamine output resulting in a hypodopaminergic system, and alters mesolimbic system functioning in response to cues that are predictive of sexual reward. Furthermore, VTA neuroplasticity is critical for the incentive motivation and reward memory, but not for the hedonic impact of sexual behavior. Finally, VTA neuroplasticity caused by natural reward behavior followed by a short period of reward abstinence influence opiate reward and may therefore affect the vulnerability to development of drug addiction.

\section{References}

Agmo A (1997) Male rat sexual behavior. Brain Res Brain Res Protoc 1:203209. CrossRef Medline

Ahmed SH, Koob GF (1998) Transition from moderate to excessive drug intake: change in hedonic set point. Science 282:298-300. CrossRef Medline

Ahmed SH, Koob GF (1999) Long-lasting increase in the set point for cocaine self-administration after escalation in rats. Psychopharmacology 146:303-312. CrossRef Medline

Ahmed SH, Walker JR, Koob GF (2000) Persistent increase in the motivation to take heroin in rats with a history of drug escalation. Neuropsychopharmacology 22:413-421. CrossRef Medline

Ahmed SH, Kenny PJ, Koob GF, Markou A (2002) Neurobiological evidence for hedonic allostasis associated with escalating cocaine use. Nat Neurosci 5:625-626. CrossRef Medline

Ahmed SH, Lin D, Koob GF, Parsons LH (2003) Escalation of cocaine selfadministration does not depend on altered cocaine-induced nucleus accumbens dopamine levels. J Neurochem 86:102-113. Medline

Aston-Jones G, Harris GC (2004) Brain substrates for increased drug seeking during protracted withdrawal. Neuropharmacology 47:167-179. CrossRef Medline

Balfour ME, Yu L, Coolen LM (2004) Sexual behavior and sex-associated environmental cues activate the mesolimbic system in male rats. Neuropsychopharmacology 29:718-730. CrossRef Medline

Balfour ME, Brown JL, Yu L, Coolen LM (2006) Potential contributions of efferents from medial prefrontal cortex to neural activation following sexual behavior in the male rat. Neuroscience 137:1259-1276. CrossRef Medline

Beitner-Johnson D, Guitart X, Nestler EJ (1992) Neurofilament proteins and the mesolimbic dopamine system: common regulation by chronic morphine and chronic cocaine in the rat ventral tegmental area. J Neurosci 12:2165-2176. Medline

Berridge KC, Robinson TE (1998) What is the role of dopamine in reward: hedonic impact, reward learning, or incentive salience? Brain Res Brain Res Rev 28:309-369. CrossRef Medline

Berridge KC, Robinson TE, Aldridge JW (2009) Dissecting components of reward: "liking", "wanting", and learning. Curr Opin Pharmacol 9:65-73. CrossRef Medline

Blum K, Werner T, Carnes S, Carnes P, Bowirrat A, Giordano J, OscarBerman M, Gold M (2012) Sex, drugs, and rock 'n' roll: hypothesizing common mesolimbic activation as a function of reward gene polymorphisms. J Psychoactive Drugs 44:38-55. CrossRef Medline

Chu NN, Zuo YF, Meng L, Lee DY, Han JS, Cui CL (2007) Peripheral electrical stimulation reversed the cell size reduction and increased BDNF level in the ventral tegmental area in chronic morphine-treated rats. Brain Res 1182:90-98. CrossRef Medline

Davis BA, Fitzgerald ME, Brown JL, Amstalden KA, Coolen LM (2007) Activation of POMC neurons during general arousal but not sexual behavior in male rats. Behav Neurosci 121:1012-1022. CrossRef Medline

Fiorino DF, Coury A, Phillips AG (1997) Dynamic changes in nucleus accumbens dopamine efflux during the Coolidge effect in male rats. J Neurosci 17:4849-4855. Medline 
Flagel SB, Clark JJ, Robinson TE, Mayo L, Czuj A, Willuhn I, Akers CA, Clinton SM, Phillips PE, Akil H (2011) A selective role for dopamine in stimulus-reward learning. Nature 469:53-57. CrossRef Medline

Frohmader KS, Pitchers KK, Balfour ME, Coolen LM (2010a) Mixing pleasures: review of the effects of drugs on sex behavior in humans and animal models. Horm Behav 58:149-162. CrossRef Medline

Frohmader KS, Wiskerke J, Wise RA, Lehman MN, Coolen LM (2010b) Methamphetamine acts on subpopulations of neurons regulating sexual behavior in male rats. Neuroscience 166:771-784. CrossRef Medline

Harris AC, Gewirtz JC (2004) Elevated startle during withdrawal from acute morphine: a model of opiate withdrawal and anxiety. Psychopharmacology 171:140-147. CrossRef Medline

Harris GC, Aston-Jones G (2003) Altered motivation and learning following opiate withdrawal: evidence for prolonged dysregulation of reward processing. Neuropsychopharmacology 28:865-871. CrossRef Medline

Hayward MD, Pintar JE, Low MJ (2002) Selective reward deficit in mice lacking beta-endorphin and enkephalin. J Neurosci 22:8251-8258. Medline

Hoebel BG, Avena NM, Bocarsly ME, Rada P (2009) Natural addiction: a behavioral and circuit model based on sugar addiction in rats. J Addict Med 3:33-41. CrossRef Medline

Hyman SE, Malenka RC, Nestler EJ (2006) Neural mechanisms of addiction: the role of reward-related learning and memory. Annu Rev Neurosci 29:565-598. CrossRef Medline

Ikemoto S, Kohl RR, McBride WJ (1997) GABA(A) receptor blockade in the anterior ventral tegmental area increases extracellular levels of dopamine in the nucleus accumbens of rats. J Neurochem 69:137-143. Medline

Jaworski J, Spangler S, Seeburg DP, Hoogenraad CC, Sheng M (2005) Control of dendritic arborization by the phosphoinositide-3'-kinase-Aktmammalian target of rapamycin pathway. J Neurosci 25:11300-11312. CrossRef Medline

Johnson SW, North RA (1992) Opioids excite dopamine neurons by hyperpolarization of local interneurons. J Neurosci 12:483-488. Medline

Klitenick MA, DeWitte P, Kalivas PW (1992) Regulation of somatodendritic dopamine release in the ventral tegmental area by opioids and GABA: an in vivo microdialysis study. J Neurosci 12:2623-2632. Medline

Koob GF, Le Moal M (2005) Plasticity of reward neurocircuitry and the "dark side" of drug addiction. Nat Neurosci 8:1442-1444. CrossRef Medline

Lennette DA (1978) An improved mounting medium for immunofluorescence microscopy. Am J Clin Pathol 69:647-648. Medline

Lett BT, Grant VL, Koh MT (2001) Naloxone attenuates the conditioned place preference induced by wheel running in rats. Physiol Behav 72:355358. CrossRef Medline

Lett BT, Grant VL, Koh MT, Flynn G (2002) Prior experience with wheel running produces cross-tolerance to the rewarding effect of morphine. Pharmacol Biochem Behav 72:101-105. CrossRef Medline

Matthews RT, German DC (1984) Electrophysiological evidence for excitation of rat ventral tegmental area dopamine neurons by morphine. Neuroscience 11:617-625. Medline

Mazei-Robison MS, Koo JW, Friedman AK, Lansink CS, Robison AJ, Vinish M, Krishnan V, Kim S, Siuta MA, Galli A, Niswender KD, Appasani R, Horvath MC, Neve RL, Worley PF, Snyder SH, Hurd YL, Cheer JF, Han $\mathrm{MH}$, Russo SJ, et al. (2011) Role for mTOR signaling and neuronal activity in morphine-induced adaptations in ventral tegmental area dopamine neurons. Neuron 72:977-990. CrossRef Medline

Mazei-Robison MS, Nestler EJ (2012) Opiate-induced molecular and cellular plasticity of ventral tegmental area and locus coeruleus catecholamine neurons. Cold Spring Harb Perspect Med 2:a012070. CrossRef Medline

Mehrara BJ, Baum MJ (1990) Naloxone disrupts the expression but not the acquisition by male rats of a conditioned place preference response for an oestrous female. Psychopharmacology 101:118-125. CrossRef Medline

Meisel RL, Mullins AJ (2006) Sexual experience in female rodents: cellular mechanisms and functional consequences. Brain Res 1126:56-65. CrossRef Medline

Miller RL, Baum MJ (1987) Naloxone inhibits mating and conditioned place preference for an estrous female in male rats soon after castration. Pharmacol Biochem Behav 26:781-789. CrossRef Medline

Mitchell JB, Stewart J (1990) Facilitation of sexual behaviors in the male rat associated with intra-VTA injections of opiates. Pharmacol Biochem Behav 35:643-650. CrossRef Medline
Murphy LO, Blenis J (2006) MAPK signal specificity: the right place at the right time. Trends Biochem Sci 31:268-275. CrossRef Medline

Nestler EJ (2012) Transcriptional mechanisms of drug addiction. Clin Psychopharmacol Neurosci 10:136-143. CrossRef Medline

Numan S, Seroogy KB (1999) Expression of trkB and trkC mRNAs by adult midbrain dopamine neurons: a double-label in situ hybridization study. J Comp Neurol 403:295-308. CrossRef Medline

Paxinos G, Watson C (2013) The rat brain in stereotaxic coordinates, Ed 7. Boston: Academic.

Pitchers KK, Balfour ME, Lehman MN, Richtand NM, Yu L, Coolen LM (2010a) Neuroplasticity in the mesolimbic system induced by natural reward and subsequent reward abstinence. Biol Psychiatry 67:872-879. CrossRef Medline

Pitchers KK, Frohmader KS, Vialou V, Mouzon E, Nestler EJ, Lehman MN, Coolen LM (2010b) DeltaFosB in the nucleus accumbens is critical for reinforcing effects of sexual reward. Genes Brain Behav 9:831-840. CrossRef Medline

Pitchers KK, Schmid S, Di Sebastiano AR, Wang X, Laviolette SR, Lehman MN, Coolen LM (2012) Natural reward experience alters AMPA and NMDA receptor distribution and function in the nucleus accumbens. PLoS One 7:e34700. CrossRef Medline

Pitchers KK, Vialou V, Nestler EJ, Laviolette SR, Lehman MN, Coolen LM (2013) Natural and drug rewards act on common neural plasticity mechanisms with DeltaFosB as a key mediator. J Neurosci 33:3434-3442. CrossRef Medline

Roux PP, Blenis J (2004) ERK and p38 MAPK-activated protein kinases: a family of protein kinases with diverse biological functions. Microbiol Mol Biol Rev 68:320-344. CrossRef Medline

Russo SJ, Bolanos CA, Theobald DE, DeCarolis NA, Renthal W, Kumar A, Winstanley CA, Renthal NE, Wiley MD, Self DW, Russell DS, Neve RL, Eisch AJ, Nestler EJ (2007) IRS2-Akt pathway in midbrain dopamine neurons regulates behavioral and cellular responses to opiates. Nat Neurosci 10:93-99. CrossRef Medline

Schultz W (2010) Multiple functions of dopamine neurons. F1000 Biol Rep 2:2. CrossRef Medline

Seroogy KB, Gall CM (1993) Expression of neurotrophins by midbrain dopaminergic neurons. Exp Neurol 124:119-128. CrossRef Medline

Shippenberg TS, Bals-Kubik R, Herz A (1987) Motivational properties of opioids: evidence that an activation of delta-receptors mediates reinforcement processes. Brain Res 436:234-239. CrossRef Medline

Sklair-Tavron L, Nestler EJ (1995) Opposing effects of morphine and the neurotrophins, NT-3, NT-4, and BDNF, on locus coeruleus neurons in vitro. Brain Res 702:117-125. CrossRef Medline

Sklair-Tavron L, Shi WX, Lane SB, Harris HW, Bunney BS, Nestler EJ (1996) Chronic morphine induces visible changes in the morphology of mesolimbic dopamine neurons. Proc Natl Acad Sci U S A 93:11202-11207. CrossRef Medline

Spiga S, Serra GP, Puddu MC, Foddai M, Diana M (2003) Morphine withdrawal-induced abnormalities in the VTA: confocal laser scanning microscopy. Eur J Neurosci 17:605-612. CrossRef Medline

Swanson LW (2004) Brain maps: structure of the rat brain, Ed 3. San Diego: Academic.

Tenk CM, Wilson H, Zhang Q, Pitchers KK, Coolen LM (2009) Sexual reward in male rats: effects of sexual experience on conditioned place preferences associated with ejaculation and intromissions. Horm Behav 55: 93-97. CrossRef Medline

Tzschentke TM (2007) Measuring reward with the conditioned place preference (CPP) paradigm: update of the last decade. Addict Biol 12:227462. CrossRef Medline

van Furth WR, van Ree JM (1996) Sexual motivation: involvement of endogenous opioids in the ventral tegmental area. Brain Res 729:20-28. CrossRef Medline

van Furth WR, Wolterink G, van Ree JM (1995) Regulation of masculine sexual behavior: involvement of brain opioids and dopamine. Brain Res Brain Res Rev 21:162-184. CrossRef Medline

Walker JR, Chen SA, Moffitt H, Inturrisi CE, Koob GF (2003) Chronic opioid exposure produces increased heroin self-administration in rats. Pharmacol Biochem Behav 75:349-354. CrossRef Medline

Young KA, Gobrogge KL, Liu Y, Wang Z (2011) The neurobiology of pair bonding: insights from a socially monogamous rodent. Front Neuroendocrinol 32:53-69. CrossRef Medline 